\title{
Reliability and reliability-based sensitivity analyses of steel moment-resisting frame structure subjected to extreme actions
}

\author{
Abbasali Sadeghi \\ Department of Civil Engineering, Mashbad Branch, Islamic Azad University, Mashbad, Iran \\ abbasali.sadeghi@mshdiau.ac.ir, bttp://orcid.org/0000-0002-3016-9080 \\ Hamid Kazemi, Mayasam Samadi \\ Department of Civil Engineering, Mashbad Branch, Islamic Azad University, Mashbad, Iran \\ kazemi0518@mshdiau.ac.ir,http://orcid.org/0000-0003-2590-1051 \\ samadi4432@mshdiau.ac.ir,bttp://orcid.org/0000-0003-4485-4174
}

\begin{abstract}
The ground external columns of buildings are vulnerable to the extreme actions such as a vehicle collision. This event is a common scenario of buildings' damages. In this study, a nonlinear model of 2-story steel moment-resisting frame $(S M R F)$ is made in OpenSees software. This paper aims investigating the reliability analysis of aforementioned structure under heavy vehicle impact loadings by Monte Carlo Simulation (MCS) in MATLAB software. To reduce computational costs, meta-model techniques such as Kriging, Polynomial Response Surface Methodology (PRSM) and Artificial Neural Network $(A N N)$ are applied and their efficiency is assessed. At first, the random variables are defined. Then, the sensitivity analyses are performed using MCS and Sobol's methods. Finally, the failure probabilities and reliability indices of studied frame are presented under impact loadings with various collision velocities at different performance levels and thus, the behavior of selected $S M R F$ is compared by using fragility curves. The results showed that the random variables such as mass and velocity of vehicle and yield strength of used materials were the most effective parameters in the failure probability computation. Among the meta-models, Kriging can estimate the failure probability with the least error, sample number with minimum computer processing time, in comparison with MCS.
\end{abstract}

KEYwORDS. Reliability; Meta-Model; Sensitivity; Impact Loading; Steel Moment-Resisting Frame.

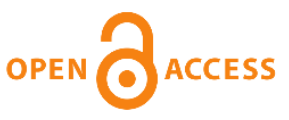

Citation: Sadeghi, A., Kazemi, H., Samadi, M., Reliability and Reliability-based Sensitivity Analyses of Steel Moment-Resisting Frame Structure subjected to Extreme Actions, Frattura ed Integrità Strutturale, 57 (2021) 138-159.

Received: 09.05.2021

Accepted: 27.05.2021

Published: 01.07.2021

Copyright: (C) 2021 This is an open access article under the terms of the CC-BY 4.0, which permits unrestricted use, distribution, and reproduction in any medium, provided the original author and source are credited.

\section{INTRODUCTION}

$\mathrm{I}$ $\mathrm{n}$ the last decade, due to the increasing terrorist threats in different parts of the world, special attention has been paid to the design and analysis of resistant structures to abnormal loadings. One of the most common accidental loading scenarios is the vehicle collision impact, which may typically happen at the ground level of a building. This scenario can lead considerable damages to the impacted column or even results to the local or global failure of a building. Based on 
the structural codes, buildings should be designed in such a way that the probable damage caused by an accidental event does not generate unsuitable effects [1]. Traditionally, structural engineers have designed and analyzed buildings against normal lateral loadings such as an earthquake and wind, but in some cases, assessing the nonlinear performance of structures against abnormal loadings is vital, too. In this regard, it is necessary for structural engineers to understand the failure behavior of buildings under intentional and or accidental impact loadings as extreme actions and then, the performance levels of structures should be specified under this loading [2]. Numerous studies are devoted to assess the influences of vehicle impact to performance of buildings and bridges. In the following, these researches are extracted from technical literatures related to this issue. El-Tawil et al. $(2003,2005)$ evaluated the performance of bridge columns under the effect of heavy vehicles impact. The results showed that the present collision design codes could be conservative and the bridge columns were vulnerable to impact loadings, so the effect of them should be considered in design procedure [3, 4]. In following, probabilistic framework is proposed by Sharma et al. $(2014,2015)$ for the assessment of dynamic shear force capacity and demand of reinforced concrete $(R C)$ columns subjected to vehicle impact using fragility curves [5, 6]. Also, the effects of different foundation connection details are investigated by Kang and Kim (2017) on performance of a steel column under vehicle impact. The results of mentioned paper indicated that the reinforcement plots were influential in reducing the damages and finally, the optimized reinforcement layout was proposed for the best reaction against this kind of loading [7]. Then, with growing the study of the structures based probability, the probabilistic analyses are recently increased these days. These analyses includes reliability evaluation and fragility curves of 3 -story steel moment-resisting frame (SMRF) that are performed by Javidan et al. (2018) in weak and strong axis directions, and compared the results between artificial neural network (ANN) and finite element analysis. The results demonstrated that the precision of $A N N$ is considerable and acceptable [8]. Recently, Santos et al. (2020) presented the results of a numerical investigation about SMRF structures subjected to vehicle impact loadings. The results of the mentioned study revealed that the vehicle impact analyses would lead to greater structural responses and critical damages especially for high collision velocities than column removal approach by using alternative-load path method (APM) [9]. Oliveira et al. (2020) proposed a simplified lumped damage model to assess the performance of $R C$ structures under impact loading with considering shear failure mode [10]. Sadeghi et al. (2021) evaluated the collapse capacity and endurance duration of $S M R F$ structure including a corner damaged column due to light vehicle impact under seismic records. The mentioned study investigated the effects of impact and earthquake loadings on performance of $S M R F$. In an aforementioned research, the damaged column scenarios are considered with 3 states. The first scenario without considering a damaged column and scenarios 2 and 3 are assumed to have a corner damaged column due to vehicle impact with velocities 60 and $120 \mathrm{~km} / \mathrm{h}$, respectively. The results showed that scenario 3 had a weaker seismic performance in comparison with other scenarios [11].

Reliability theory is a branch of general probability theory that has gradually applied in engineering platform over the last four decades. Today, computer simulations are a favorite gadget to analyze, design, and optimize structural systems against various loadings. Therefore, in recent years, probabilistic analyses including application of the reliability-based simulation methods are growing for failure mechanism evaluation of structural systems. Also, assessing performance of a structure under extreme loadings needs huge nonlinear dynamic analyses to specify failure probability. To get a solution for this issue, numerous mathematical techniques have been proposed called meta-models [12]. The research background of reliability field using meta-models is presented in the following. Kim et al. (2011) studied the sensitivity analysis of design variables of $2 D S M R F$ and concentric braced frame (CBF) under progressive collapse. To this goal, Monte Carlo Simulation (MCS), tornado diagram analysis (TDA), and first-order second moment (FOSM) methods are conducted with regarding to the different uncertainties. The new findings showed that the beam yield strength and column yield strength were the most important uncertainty in $S M R F$ s and $C B F s$, respectively [13]. Also, the reliability analyses of seismic performance of $R C$ and SMRFs are studied by Gholizadeh et al. (2014). For this aim, the above mentioned frames are designed optimally. Then, MCS is utilized to estimate the total exceedance probability related to different performance levels. Then, two surrogate models such as radial basis function $(\mathrm{R} B F)$ and back propagation $(B P)$ are applied for predicting the structural responses. The results showed that the superiority of $B P$ to $R B F$ in prediction of structural responses related to structural performance levels [14]. In the following, a developed probabilistic framework based on Kriging meta-model is presented by Gidaris et al. (2015) for seismic risk assessment using stochastic ground motion models to describe the seismic hazard [15]. Vazirizade et al. (2017) used $A N N$ to reduce the computational costs required for reliability analysis and damage detection of steel structures [16]. As well as, ANN surrogate model is applied by Hashemi et al. (2018) for predicting the quantity of used steel materials in $S M R F$ structures. The results demonstrated that the weights of structures could be approximated using $A N N$ with an admissible precision [17]. Hadianfard et al. (2018) assessed the reliability theory and taking into account the different uncertainties related to blast loading and material properties. The results indicated that assessing the damage index of the columns against the blast was important with considering the random parameters [18]. In this regard, Hedayat et al. (2019) showed that the proposed formula developed based on $A N N$ and Bilin element of the OpenSees software to anticipate the 
minimum strength requirement of $S M R F s$ at any performance levels. Also, it was clear that $A N N$ was more precise than the other available surrogate models [19]. In the following, the reliability indices of structural systems are calculated by Hoseini Vaez et al. (2020) with an implicit limit state function (LSF). Then, in order to decrease the computational costs of MCS, the reliability indices obtained by using meta-heuristic algorithms [20]. Recently, Rahgozar et al. (2021) evaluated the seismic reliability of controlled-rocking steel cores (CRSCs) with considering a set of uncertainty parameters. The findings of this study showed that the design process was reliable and the safety of CRSCs is considered; however, the probability failure for mid-rise CRSCs was more than low-rise prototypes [21].

Apart from the above mentioned studies, very little attention has been paid to experimental researches for understanding the structural behavior of buildings against vehicles collision due to its setup and an expensive procedure [22, 23]. Therefore, this is a major reason for developing the analytical models based on probabilistic approaches to perceive the performance of buildings under vehicle impact. In this study, a 2-story $S M R F$ structure with intermediate ductility is designed based on regulations, and nonlinear dynamic analyses are performed using OpenSees software [24]. Then, sensitivity analyses using $M C S$ and Sobol's methods are conducted by MATLAB [25]. As a significance and novelty, a probabilistic versatile framework is proposed based on the reliability analyses under heavy vehicle impact loadings with different collision velocities using MCS, meta-models including Kriging, Polynomial Response Surface Methodology (PRSM) and Artificial Neural Network $(A N N)$ are considered for reducing computational costs, while having high accuracy and least error rate. Finally, it may provide a throughout framework based on probabilities under vehicle impact loadings, which has gained great interest in practical researches in this field. Moreover, the comparison of different sensitivity tests results will show the important random variables and at last, the best meta-model will be specified by using reliability and fragility analyses which is useful and practical for future researchers in this aspect.

\section{STRUCTURAL RELIABILITY ANALYSIS}

he performance of structural systems is assessed mathematically in term of reliability analysis by failure criteria. These failure levels are usually specified by structural damage levels. In this regard, for both reliability and sensitivity analyses, $M C S$ is applied by producing a large number of samples and assessing their structural responses due to statistical distributions. In spite of its easiness and power, this approach requires high computer processing time and much more cost. As a result, many methods such as meta-models have been proposed by researchers to solve this problem [26, 27]. Therefore, the introduction of MCS and meta-models are briefly explained in the following.

\section{MCS and score function approach}

MCS is a reliability based simulation method that is widely used in structural reliability of different problems. Based on statistical sampling theory, $M C S$ solves structural reliability by statistical sampling of random variables mathematically [26, 28]. MCS can be applied for complex problems including material and geometric nonlinearity and high dimensional that cannot be solved analytically. In this route, considering $x$ and $g(x)$ as the uncertain quantities and the performance function of the structural systems, respectively. In the following, the failure probability $\left(P_{f}\right)$ is estimated using Eqn. 1 [26, 28]:

$$
\boldsymbol{P}_{f}=\int_{g(x) \leq 0} f_{x}(x) d x=\int_{\mathbb{X}} \mathbb{I}_{g(x) \leq 0}(x) f_{x}(x) d x=\mathbb{E}_{f}\left(\mathbb{I}_{g(x) \leq 0}(x)\right)
$$

According to Eqn. (1), $\mathbb{E}_{f}$ is the expectation operator, $f_{x}$ is the probability density function $(P D F)$ of random variables $x$, the function $g(x) \leq 0$ shows the failure set and $\mathbb{I}_{g(x) \leq 0}$ is an indicator function that is specified in Eqn. 2. Also, based on this equation the parameter $x^{i}$ is the $i$ th random variable and when the indicator function $\mathbb{I}_{g(x) \leq 0}$ is 0 and 1 , it means that the samples are considered in safe and failure regions, respectively.

$$
\mathbb{I}_{\boldsymbol{g}(\boldsymbol{x}) \leq 0}(\boldsymbol{x})=\left\{\begin{array}{l}
0, x^{i} \notin(g \leq 0) \\
1, x^{i} \in(g \leq 0)
\end{array}\right.
$$


The reliability index $(\beta)$ is computed using the first-order approximation with regarding to Eqn. 3, where $\Phi^{-1}$ is the inverse cumulative distribution function of the standard normal distribution [8].

$$
\beta=-\phi^{-1}\left(P_{f}\right)
$$

In this regard, independent and identically distributed (iid) samples $\left[x^{i}: i=1, \ldots, N\right]$ are generated according to PDF of $\left(f_{x}\right)$ and evaluating $\mathbb{E}_{f}\left(\mathbb{I}_{g(x) \leq 0}(x), M C S\right.$ only provides an exact failure probability for any kind of structural systems [26]. Also, the partial derivative of the failure probability related to a statistical specification of the $i-t h$ random variable i.e. $\xi_{i}$ can be determined with Eqn. 4:

$$
\frac{\partial \boldsymbol{P}_{\boldsymbol{f}}(\boldsymbol{\xi})}{\partial \boldsymbol{\xi}_{\boldsymbol{i}}}=\frac{\partial}{\partial \xi_{i}} \int_{\mathbb{X}} \mathbb{I}_{F}(x) \partial f_{X}(x, \xi) d x
$$

Then, Lebesgue dominated convergence theory and importance sampling (IS) are used and in the following, Eqn. 4 would be rewritten as Eqn. 5 [26, 28, 29]:

$$
\begin{aligned}
\frac{\partial \boldsymbol{P}_{f}(\boldsymbol{\xi})}{\partial \xi_{i}} & =\int_{\mathbb{X}} \mathbb{I}_{F}(x) \frac{\partial f_{X}(x, \xi)}{\partial \xi_{i}} d x=\int_{\mathbb{X}} \mathbb{I}_{F}(x) \frac{\partial f_{X}(x, \xi)}{\partial \xi_{i}} \frac{f_{X}(x, \xi)}{f_{X}(x, \xi)} d x= \\
& =\int_{\mathbb{X}} \mathbb{I}_{F}(x) \frac{\partial f_{X}(x, \xi) / \partial \xi_{i}}{f_{X}(x, \xi)} f_{X}(x, \xi) d x= \\
& =\int_{\mathbb{X}} \mathbb{I}_{F}(x) \frac{\partial \log f_{X}(x, \xi)}{\partial \xi_{i}} f_{X}(x, \xi) d x=\mathbb{E}_{X}\left[\mathbb{I}_{F}(X) \cdot \mathbb{K}_{i}(X, \xi)\right.
\end{aligned}
$$

Therefore, the so-called score function presented as Eqn. 6:

$$
\mathbb{K}_{i}(\boldsymbol{x}, \boldsymbol{\xi})=\frac{\partial \log f_{X}(x, \xi)}{\partial \xi_{i}}
$$

Also, it is recommended that researchers refer to the authentic papers [26, 29] for more information about MCS and score function. With regarding to high computational efforts of $M C S$, application of meta-model techniques in structural reliability problems has been developed and proposed [30, 31, 32].

\section{Meta-models}

In recent years, meta-models are widely used among researchers over the world to reduce the computational costs of the reliability analyses by predicting the structural responses [33]. Meta-model techniques can provide an accurate representation of the PDF of the model response. Some meta-models, such as Kriging [34, 35], PRSM [36], and ANN [8] have been successfully applied for structural reliability problems that are briefly presented in the following sections.

\section{Kriging}

Kriging is a mathematical interpolation approach for constructing a surrogate model instead of the original prototype. Kriging surrogate model is widely applied in reliability evaluation and failure probability computation of problems. This method aims to minimize the error rate and fit the mean of the prediction errors to zero [37]. Also, considering support points and related response $Y$ as $Y=\left[G\left(x_{1}\right), \ldots, G\left(x_{s}\right)\right]^{T}$, Kriging meta-model presents the definite response $G(x)$ as a realization of a random function [36]. The function $G(x)$ is presented as Eqn. 7:

$$
G(x)=f^{T}(x) \beta+z(x)
$$


As well as, in Eqn. (7), $f(x)=\left[f_{1}(x), \ldots, f_{m}(x)\right]^{T}$ is a vector of $m$ basis functions; and $\beta=[\beta(x), \ldots, \beta(x)]^{T}$ indicates the vector of $m$ regression coefficients. Also, the parameter $z(x)$ specifies a stationary Gaussian process with zero mean, the parameter $\sigma^{2}$ is the process variance, and the parameter $\mathrm{R}\left(x_{i}, x_{j}\right)$ represents the correlation function between samples $x_{i}$ and $x_{j}$. The following covariance function is presented according to Eqn. 8:

$$
\operatorname{cov}\left(z\left(x_{i}\right), z\left(x_{j}\right)\right)=\sigma^{2} R\left(x_{i}, x_{j}\right)
$$

The Gaussian type, which is the widely used correlation function, defined as Eqn. 9:

$$
\boldsymbol{R}\left(\boldsymbol{x}_{\boldsymbol{i}}, \boldsymbol{x}_{\boldsymbol{j}}\right)=\prod_{i=1}^{n} \exp \left(-\theta_{1}\left(x_{i, 1}-x_{j, 1}\right)^{2}\right)
$$

In which $x_{i, 1}$ is the first component of vector $x_{i}$; and $\theta_{1}$ is the first correlation parameter. These parameters can be evaluated and approximated by the maximum probability method [37].

Polynomial response surface methodology (PRSM)

PRSM is a proper surrogate model for the structural cases where the closed form expression is not specific for the performance function. This meta-model is first presented by Box and Wilson [36], and Faravelli [38] in structural reliability problems and it is still popular topic for further studies among researchers [39-42]. The predicted structural responses by this method can be presented as Eqn. 10:

$$
\boldsymbol{y}=X \beta+\varepsilon_{y}
$$

Where the parameters $X, \beta$ and $\varepsilon_{y}$ are input data vector, unknown coefficient vector and error vector, respectively. Response surface can be mathematically defined for a typical quadratic polynomial basis as Eqn. 11:

$$
\boldsymbol{y}=\beta_{0}+\sum_{i=1}^{k} \beta_{i} x_{i}+\sum_{i=1}^{k} \sum_{j=1}^{k} \beta_{i j} x_{i} x_{j}
$$

The least-squares method ( $L S M)$ is used for unknown polynomial coefficients. They can be approximated by minimizing the error rate based on Eqn. 12:

$$
\boldsymbol{e}(\boldsymbol{\beta})=\sum_{i=1}^{n}\left(y_{i}-\beta_{0} \sum_{i=1}^{k} \beta_{i} x_{i}-\sum_{i=1}^{k} \sum_{j=1}^{k} \beta_{i j} x_{i} x_{j}\right)^{2}=(y-x \beta)^{T}(y-x \beta)
$$

Also, based on $L S M$, the parameter $\beta$ is approximated and extracted according to Eqn. 13:

$$
\boldsymbol{\beta}=\left[X^{T} X\right]^{-1}\left\{X^{T} y\right\}
$$

In this method, the initial input data $(X$ and $y)$ should be selected carefully to proportionate an accurate function [38].

\section{Artificial neural network (ANN)}

Today, neural network (NN) methods are widely used in engineering issues as meta-model. The basis of $N N$ approach which named weight function, is very flexible and trainable for different kind of functions, so there is no limitation on the shape, size, importance, or type of function [8]. The goal of $A N N$ surrogate model is mapping from an input variable space to a response space using a number of simple mathematical models called artificial neurons. Each neuron includes the input 
channels receiving the input vector $\left[x_{i}\right]$, weight vector $\left[w_{i}\right]$, bias $b$, transfer function $f$, and one output channel $y$. This mathematical process is shown in Fig. 1.

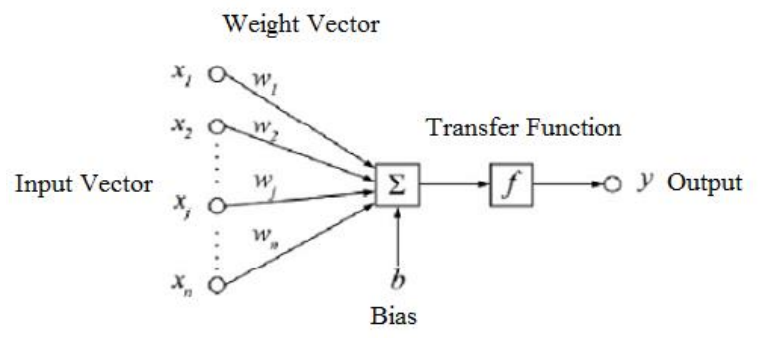

Figure 1: Mathematical procedure of $A N N[8]$.

The input signals are multiplied by the weights and summed with the bias as a corrective term. To produce the output $y$, the summation is input to the transfer function which is usually one of the Linear, Tan-sigmoid, Log-sigmoid, or Step functions [43, 44]. This method with consideration of the Tan-sigmoid function can be defined as Eqns. 14 and 15:

$$
\begin{aligned}
& \boldsymbol{y}=f(w \cdot x+b) \\
& \boldsymbol{F}(\boldsymbol{x})=\frac{2}{1 \pm e^{-2 x}}-1
\end{aligned}
$$

The given parameters such as input vector, the weight vectors and bias must be well-balanced in order to anticipate the structural responses exactly. The connecting neurons to each other and regulating them with a proper network architecture leads to a regular framework called $A N N s$ [44].

\section{MODELING PROCEDURE}

$\mathrm{I}$

$\mathrm{n}$ this study, a three-dimensional 2-story $S M R F$ with intermediate ductility is considered as the prototype structure for an analysis model. This structure is loaded based on ASCE07 [45] and design control criteria of the ASCE07 and AISC-360 [46] are checked and confirmed. Seismic design category type $D$ is assume. The story height, and the span length were 3.2 and $6 \mathrm{~m}$, respectively. In the following, the both dead and live loads are assumed as gravity loadings. The applied values for distributed dead and live loads to all stories were taken 500 and $200 \mathrm{~kg} / \mathrm{m}^{2}$, respectively. By checking the results of prototype design, it is observed that the dominant design criterion in building was drift control, therefore the values of demand to capacity ratio in all its structural elements were far less than one. Critical Rayleigh damping ratio is considered 0.05 , for all vibration modes of the structure and the effect of non-structural elements was ignored. All seismic requirements are applied for the prototype structure. Then, the two-dimensional frame of the side axis is extracted and modeled in OpenSees software for nonlinear dynamic analyses under impact loadings. The applied dead and live loads to this frame were 1500 and $600 \mathrm{~kg} / \mathrm{m}$, respectively. The materials used in the beams and columns were ST37 with elasticity modulus, yield stress and ultimate stress of $200 \mathrm{GPa}, 240 \mathrm{MPa}$ and $370 \mathrm{MPa}$, respectively. The bilinear uniaxial steel materials with kinematic and isotropic stiffness are assumed based on Steel01 model with a post-yielding stiffness of 3\% [13]. For structural sections, nonlinear fiber elements are used for all members as a distributed plasticity model. Therefore, in this paper, the performance of steel building is investigated under vehicle impact loading to the external corner column as a research scenario. To estimate the failure probability, uncertainties in materials and applied loadings have been noticed in the modeling and analyses and then, LSFs are considered according to the maximum permitted beam rotation of damaged bay for different performance levels. The behavior of the frame is evaluated under impact loadings caused by a heavy vehicle collision with considering the effect of $P-\Delta$. Also, building plan view and determination the exterior frame enclosed in the red rectangle, elevation of $2 D$ frame, and location of impacted column by vehicle collision are illustrated in Figs. 2 to 4 , respectively.

Tab. 1 shows the designed members' cross sections of a 2-story SMRF. Also, the overall scheme of the developed probabilistic flowchart of the current study is presented in Fig. 5. This developed flowchart summarizes the present research stages. It includes sampling generation, designing and nonlinear dynamic analyses, and then reliability, fragility, and sensitivity analyses. 


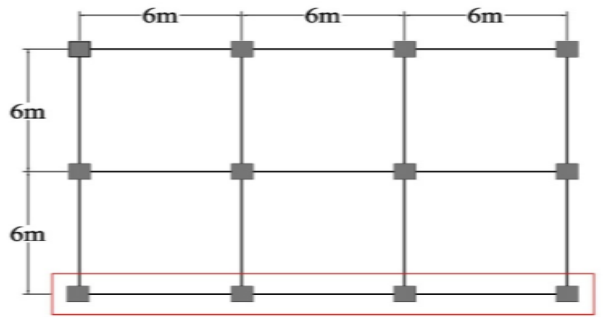

The Studied Frame

Figure 2: Building plan view and location of the studied frame.

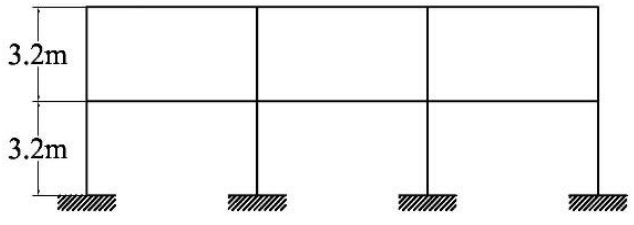

Figure 3: Elevation of a 2-story SMRF.

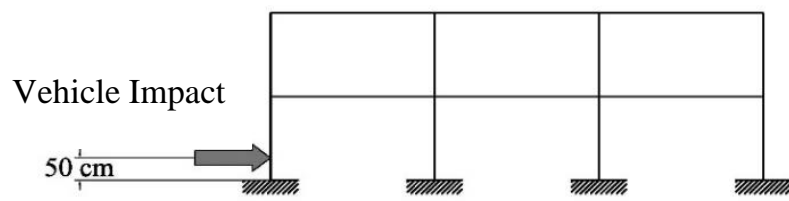

Figure 4: Location of vehicle impact to corner column.

\begin{tabular}{ccccc}
\hline \multirow{2}{*}{ Story } & \multicolumn{2}{c}{ Beam sections } & \multicolumn{2}{c}{ Column sections } \\
& Internal & External & Internal & External \\
1 & IPE200 & IPE220 & BOX200*20 & BOX200*20 \\
2 & IPE180 & IPE200 & BOX200*18 & BOX200*18 \\
\hline
\end{tabular}

Table 1: The designed cross sections of beam and column of 2-story SMRF.

In this probabilistic framework, the $S M R F$ model is first verified, and then the structural modeling procedure is performed in OpenSees software to generate the analysis numerical prototype parametrically. Three meta-models such as Kriging, PRSM and $A N N$ are conducted in the MATLAB programming code which is trained by the samples from the studied frame that is extracted from finite element analysis by OpenSees software. Accordingly, determination of uncertainty parameters, assigning them and number of samples for training procedure can be applied in the current introduced framework based on Fig. 5. At the next stage, for comparison the aforementioned surrogate models in the same conditions, three meta-models are trained with the similar samples to conduct probabilistic analyses at a low computational costs. In the following, the applicability of the present framework for probabilistic analyses under vehicle impact loadings is investigated and compared when uncertainties in loading, geometry, and material properties are completely applied. Then fragility curves are proposed by exact method and meta-model with the best performance for assessing the behavior of SMRF model. Finally, the suitable meta-model will be specified for vehicle impact scenario.

\section{Verification of modeling}

In this study, to indicate the performance, precision, and effectiveness of the developed probabilistic framework, a SMRF structure is separately verified under impact and seismic loadings. At first, Kang and Kim (2017) investigated the performance of a steel column of $S M R F$ standing on a $R C$ footing when the impact loading induced by collision of truck with an eightton was exerted. The specifications of model are presented in reference paper [7]. According to Fig. 6, the displacementtime curve of the analysis model is extracted and compared with the reference prototype. The results showed that they have a relatively good agreement with each other. 


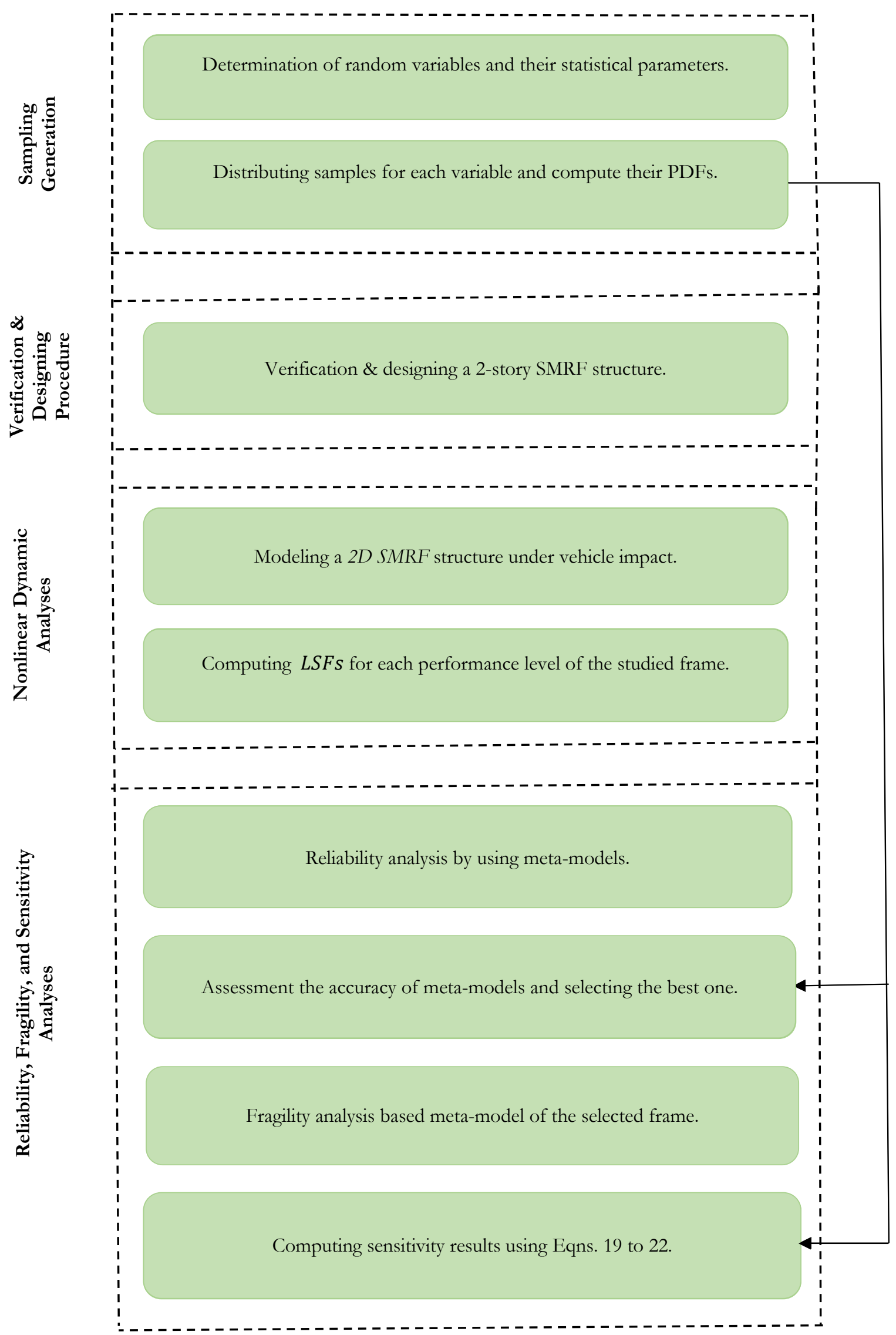

Figure 5: Representation the flowchart of the current study. 


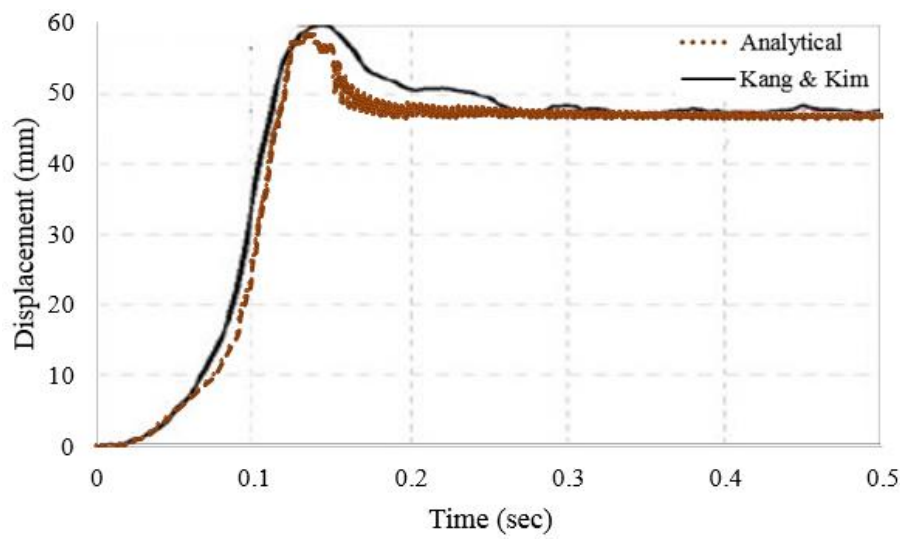

Figure 6: Comparison of displacement-time curve of analytical model versus reference model.

\section{Impact loading scenario}

Impact loading is applied to the structure dynamically with high intensity and short duration. Types of impact loadings include the vehicles impact hitting to the columns of steel, concrete buildings and or bridge piers and the impact induced by a sudden start or stop of a crane or elevator. An example of impact time history loading applied to the various heights of the building is shown in Fig. 7 [47].

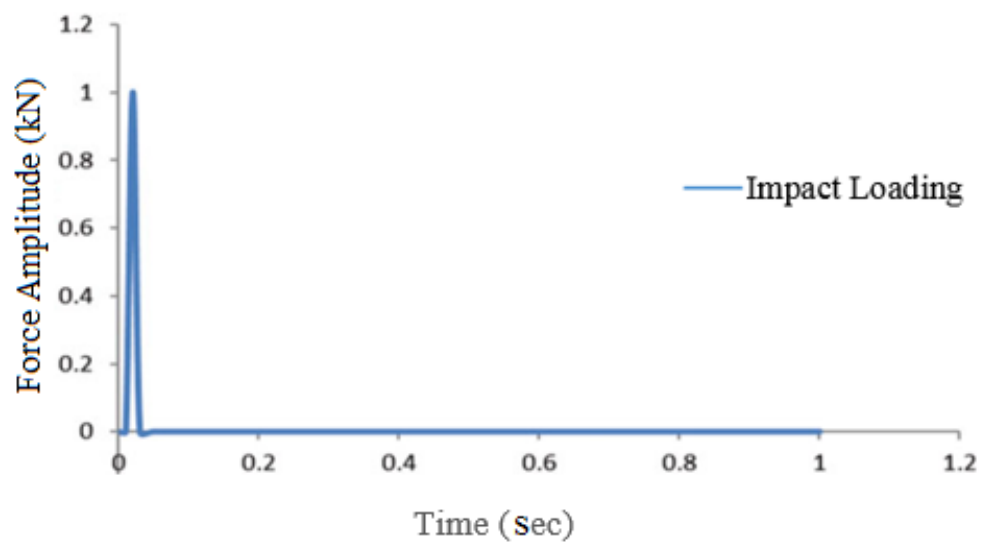

Figure 7: Time history of Impact loading due to vehicle collision [47].

The European Standard for accidental actions is considered for vehicle impact loadings [1]. According to previous studies, a heavy vehicle with $8 t$ mass is considered that collides at a height of $50 \mathrm{~cm}$ of the frame column. In this study, several vehicle velocities including 10, 20,30, 40 and $50 \mathrm{~km} / \mathrm{h}$ are assumed [1]. The impact force and impact duration in terms of vehicle velocity, stiffness, and mass are obtained from Eqns. 16 and 17, with $V$, $k$ and $m$ signs, respectively [48, 49]:

$$
\begin{aligned}
& \mathbf{F}=V \sqrt{\mathrm{km}} \\
& \Delta \boldsymbol{t}=\frac{m \cdot V}{\mathrm{~F}}
\end{aligned}
$$

\section{The limit state function (LSF)}

In this paper, MCS and meta-models are used to calculate the failure probability of studied frame. For this purpose, at first, the existing samples in the safe and failure regions are specified, and then by performing nonlinear dynamic analyses by finite element software, the LSFs of the reliability problems are evaluated. In each structural analysis, the random variables are defined based on the selected PDFs. A total of nine random variables are considered which are shown in Tab. 2. They are used to propose versatile probabilistic framework. The uncertainty parameters are classified into four categories including gravity load, material, geometric characteristics, and impact load due to the collision of a heavy vehicle. These 
variables include: yield strength and elasticity modulus of the used materials, beam length, column height, live load, dead load, and finally, the impact loading due to the heavy vehicle collision. On the one hand, the response parameters of the structure are assumed constant for achieving reasonable conclusion in order to compare the parameters of probabilistic properties. According to building regulations and technical literatures, these indicators are usually based on performance levels related to damage levels of structures. Tab. 2 presents the category, symbol, unit and references of all random variables and then their statistical characteristics such as mean, coefficient of variation, standard deviation values, and PDF of the uncertainty parameters.

\begin{tabular}{|c|c|c|c|c|c|c|c|}
\hline Category & Symbol & Description & Unit & PDF & Mean & c. $\mathrm{O} . \mathrm{v}$ or $\sigma$ & References \\
\hline \multirow{2}{*}{$\begin{array}{l}\text { Gravity } \\
\text { Load }\end{array}$} & $\mathrm{DL}$ & Dead Load & $\mathrm{kg} / \mathrm{m}$ & $\mathrm{N}$ & 1500 & 0.1 & {$[8,49]$} \\
\hline & LL & Live Load & $\mathrm{kg} / \mathrm{m}$ & G & 600 & 0.4 & {$[8,49]$} \\
\hline \multirow{2}{*}{ Material } & $\mathrm{F}_{\mathrm{y}}$ & Yield Strength & $\mathrm{MPa}$ & $\mathrm{LN}$ & 240 & 0.07 & {$[8,50]$} \\
\hline & $\mathrm{E}$ & $\begin{array}{l}\text { Modulus of } \\
\text { Elasticity }\end{array}$ & $\mathrm{MPa}$ & $\mathrm{LN}$ & $2 * 10^{5}$ & 0.03 & {$[51,52]$} \\
\hline \multirow{2}{*}{ Geometric } & $\mathrm{L}$ & Beam Length & $\mathrm{m}$ & $\mathrm{N}$ & 6 & 0.0304 & {$[50,51]$} \\
\hline & $\mathrm{H}$ & $\begin{array}{l}\text { Column } \\
\text { Height }\end{array}$ & $\mathrm{m}$ & $\mathrm{N}$ & 3.2 & 0.0304 & {$[50,51]$} \\
\hline \multirow{3}{*}{$\begin{array}{l}\text { Impact } \\
\text { Load }\end{array}$} & $\mathrm{K}$ & Stiffness & $\mathrm{kN} / \mathrm{m}$ & $\mathrm{LN}$ & 300 & $60(\mathrm{kN} / \mathrm{m})$ & {$[1,50]$} \\
\hline & M & Mass & $\mathrm{kg}$ & $\mathrm{N}$ & 8000 & $4000(\mathrm{~kg})$ & {$[1,50]$} \\
\hline & $\mathrm{V}$ & Velocity & $\mathrm{km} / \mathrm{h}$ & $\mathrm{LN}$ & 40 & $8(\mathrm{~km} / \mathrm{h})$ & {$[1,50]$} \\
\hline
\end{tabular}

* N: Normal, LN: Lognormal, G: Gamma

Table 2: List of uncertainty parameters.

In recent decades, the different damage modes of steel structures have been specified against extreme loadings, and damage levels commensurate with performance levels of structures can be established. Their corresponding LSFs are defined according to the reference book "structural design for physical security - state of the practice" [53] as shown in Tab. 3. These limit states and failure criteria such as $\mathrm{LSF}_{1}, \mathrm{LSF}_{2}$ and $\mathrm{LSF}_{3}$ are related to three damage levels of steel structures subjected to extreme loads which are associated with the light, moderate, and severe damage states, respectively.

\begin{tabular}{ccccc}
\hline \multirow{2}{*}{ Element } & Failure type & \multicolumn{3}{c}{ Damage Levels } \\
\cline { 3 - 4 } & & Light (rad) & Moderate (rad) & Severe (rad) \\
\hline Beam & Bending & 0.05 & 0.12 & 0.25 \\
\hline
\end{tabular}

Table 3: Failure criteria for steel structures under extreme loads [53].

The damage rate of studied frame is calculated based on the maximum permitted beam rotation of damaged bay as a structural response through nonlinear dynamic analyses at each failure level. Therefore, the structural collapse has occurred, when the values of beam rotation become over $25 \%$. (i.e. severe damage state). Then, by calculating the structural responses by using OpenSees software, MCS is applied for reliability analyses and comparing the failure probability of studied model. Moreover, to reduce the computational efforts, three meta-model techniques including Kriging, PRSM and $A N N$ are also used for reliability analyses. The estimated structural responses by these approaches are also compared with MCS and the accuracy rate of them is assessed and finally, the suitable meta-model will be chosen for predicting the structural responses in present scenario. 


\section{RESUlTS AND DisCUSSION}

\section{Reliability analysis using Meta-models}

T $\mathrm{n}$ this study, constructing surrogate models, 3000 random samples are generated based on the specified statistical distribution for each random variable inserted in Tab. 2 based on its statistical characteristics by augmenting standard deviations of random variables. For a sample size specified for each reliability method, a combination of generated samples is randomly set as input variables. The beam rotation of damaged bay of selected frame is calculated and then, 2000 random samples and the corresponding beam rotation of mentioned frame is opted to train the introduced metamodels randomly. Then, 1000 samples are opted to test the surrogate models. The remaining samples are utilized to test the surrogate models for predicting beam rotation of frame i.e. estimation the LSF values. In this paper, the coefficient $\left(R^{2}\right)$, was applied in order to specify the performance of the meta-models. The details of the coefficient $R^{2}$ computation could be explained more in $[54,55,56]$. The coefficient $R^{2}$ has been utilized as necessary quality criteria in different kinds of engineering applications.

In this section, the performance of three meta-models such as Kriging, PRSM and $A N N$ is investigated in predicting the beam rotation. Then, for 90 samples that are selected randomly, the values of predicted beam rotation versus the corresponding actual outputs are presented in Figs. 8 to 10 for different $L S F$ s, respectively. Also, in each graph, the fitted linear lines are also plotted (black lines) to show the performance of the meta-models. The values of $\mathrm{R}^{2}$ with respect to 90 samples were estimated at 0.96, 0.93, and 0.91, for three LSFs respectively, showing the best ability of Kriging surrogate model in structural response prediction. In other words, in all $L S F s$, it is clear that a strong linear correlation between actual and predicted beam rotation values is related to the Kriging surrogate model and it has the least error for predicting the structural responses. Therefore, this method is recommended to be used in the vehicle collision impact scenarios.

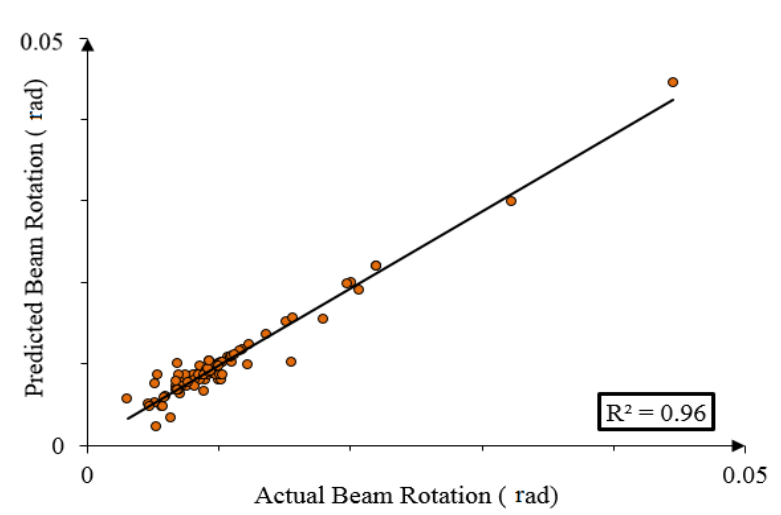

a) Kriging

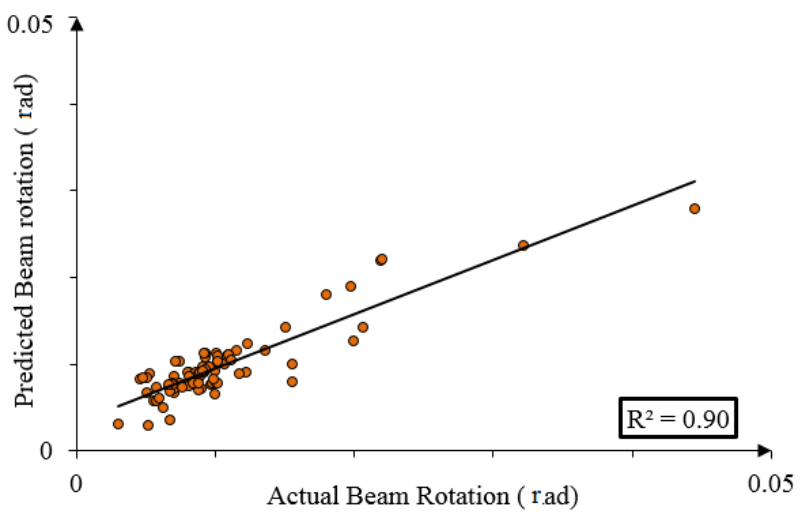

b) PRSM

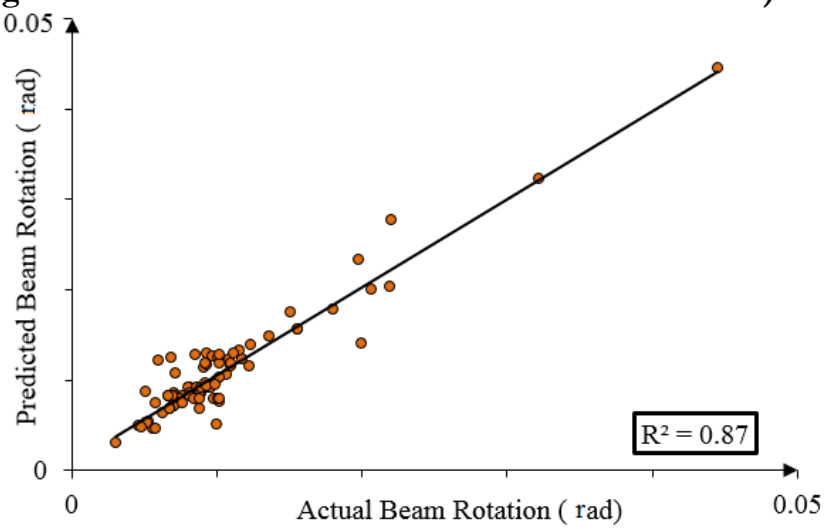

c) $\boldsymbol{A N N}$

Figure 8: Regression graphs between predicted and actual values of beam rotation using the studied meta-models for $L S F_{1}$. 


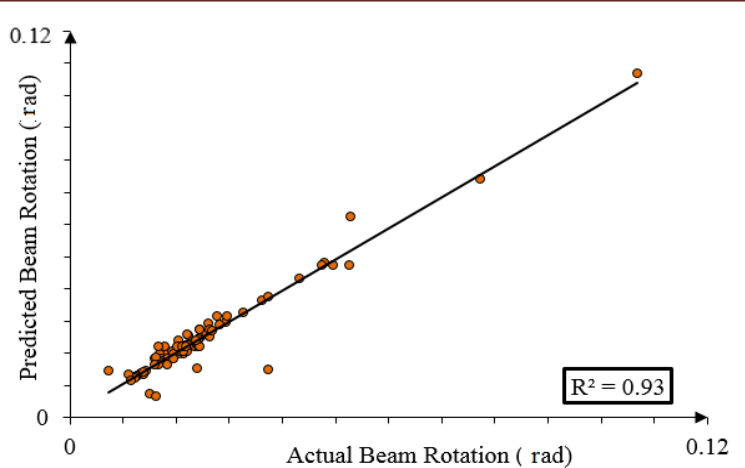

a) Kriging

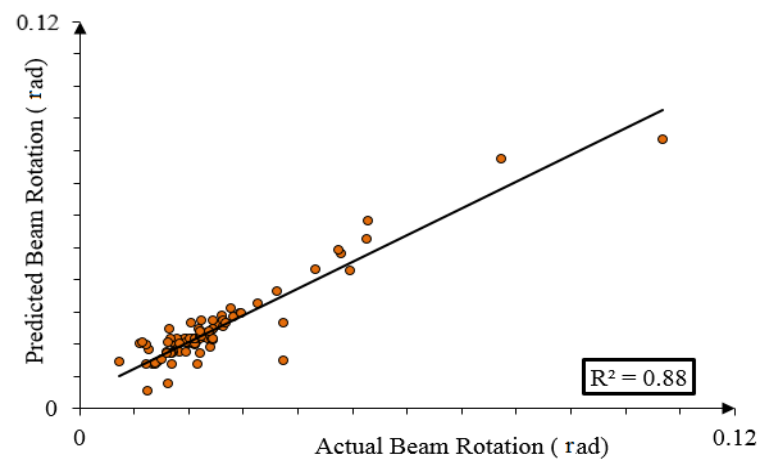

b) PRSM

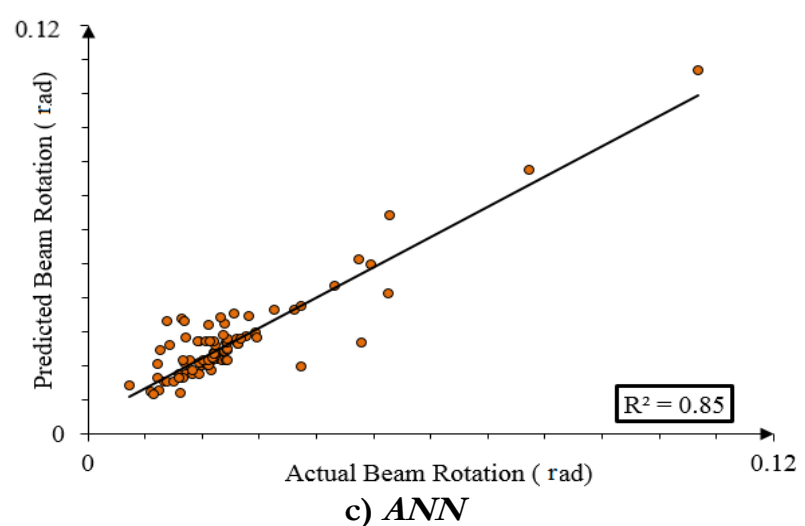

Figure 9: Regression graphs between predicted and actual values of beam rotation using the studied meta-models for $\mathrm{LSF}_{2}$.

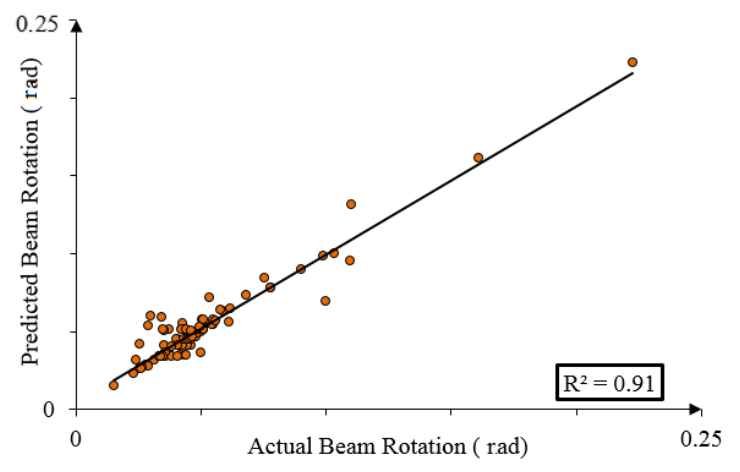

a) Kriging

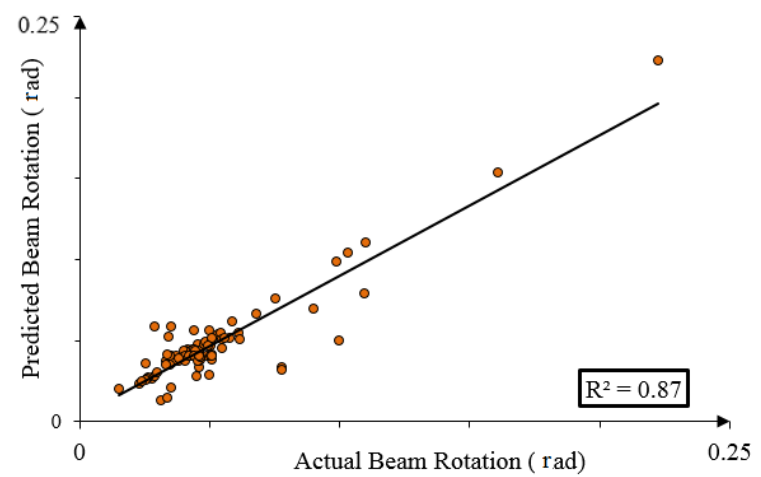

b) PRSM

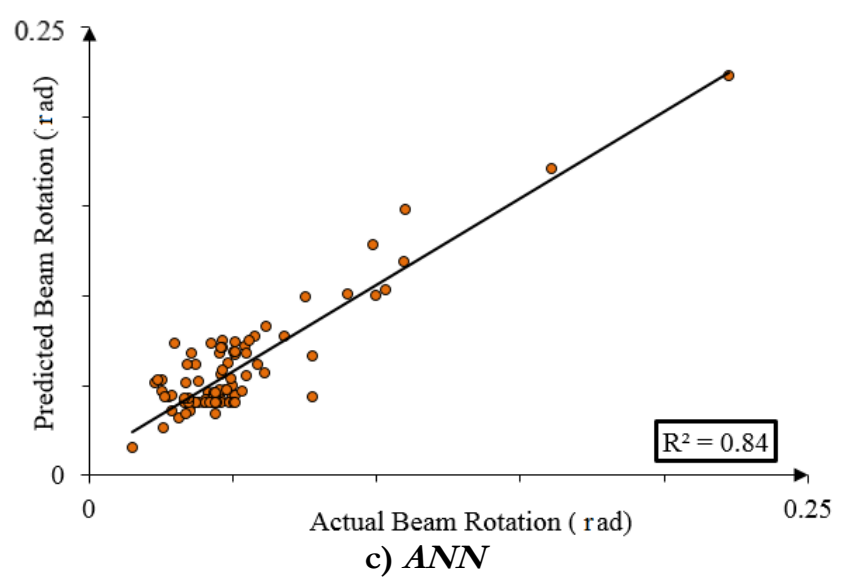

Figure 10: Regression graphs between predicted and actual values of beam rotation using the studied meta-models for $L S F_{3}$. 
Fig. 11 (a) to (c) indicate the reliability index of aforementioned frame in terms of the mean of different velocity values in range 0 to $50 \mathrm{~km} / \mathrm{h}$ for $L S F_{1}, L S F_{2}$ and $L S F_{3}$, respectively. As it can be seen, by increasing the mean vehicle velocity from 0 to $50 \mathrm{~km} / \mathrm{h}$ for $L S F_{1}, L S F_{2}$ and $L S F_{3}$, the reliability index decreased by $13 \%, 20 \%$ and $18 \%$, respectively. Also, for example, in $\mathrm{LSF}_{3}$, the reliability index difference of $S M R F$ for Kriging versus MCS in vehicle velocities 10, 20,30, 40 and $50 \mathrm{~km} / \mathrm{h}$ are 0.62, 0.95, 0.66, 0.34 and 0.58, respectively. Based on Fig. 11 (a) to (c), the obtained values of reliability index in metamodels and MCS are compared with each other, it is found that kriging surrogate model has the highest accuracy for all three LSFs with regarding to variation of the mean value of vehicle velocity. Moreover, PRSM and ANN meta-models achieved the $2^{\text {nd }}$ and $3^{\text {rd }}$ ranking in estimating the reliability indices of aforementioned frame with regarding to the mean value of vehicle velocity variations.

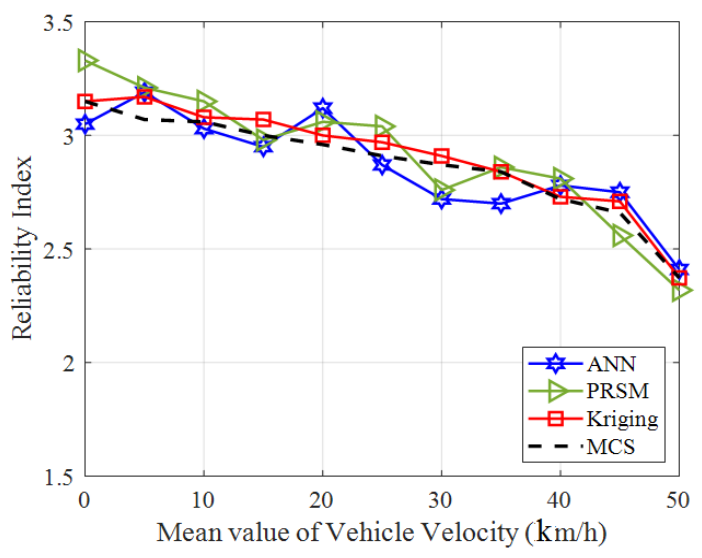

a) $L_{S F_{1}}$

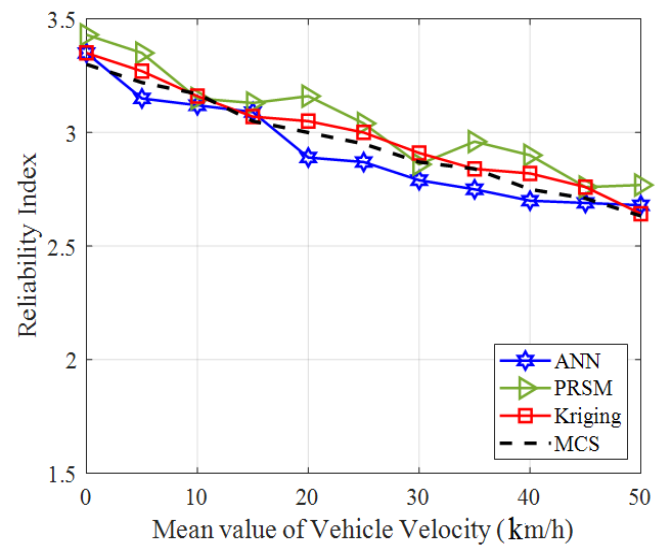

b) $L S F_{2}$

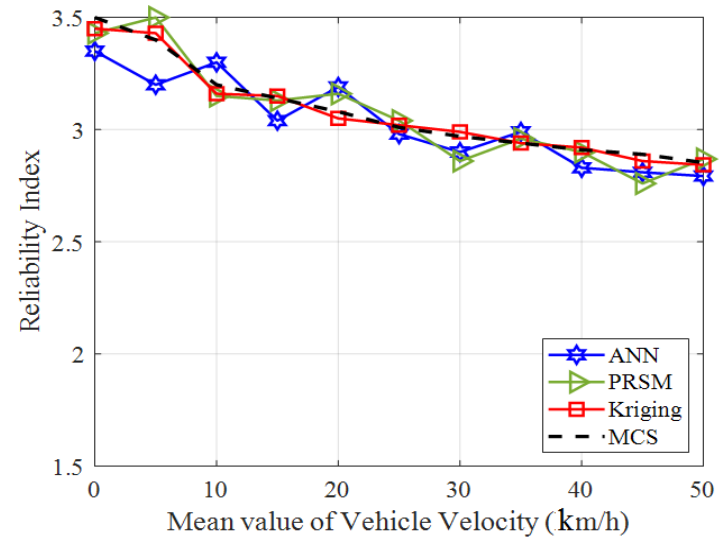

c) $\mathrm{LSF}_{3}$

Figure 11: Reliability index obtained due to mean value of vehicle velocity variation based on the studied LSFs.

For different number of support points, the reliability problem is solved for three LSFs to investigate the sensitivity of applied meta-model techniques to the number of samples and employed DoE strategy. Fig. 12 (a) to (c) indicate that for 2000 support points, the accuracy of three meta-models are improved versus MCS. These Figures illustrate that Kriging surrogate model provided the best solution for the reliability problem. Similar results are obtained for the other two LSFs. In this section, to perform reliability analyses of representative frame subjected to vehicle impact using meta-models, for some random input samples of each variable, the corresponding beam rotation with those variables are predicted by Kriging surrogate model. For 3000 random samples, the frequency Histogram of the predicted responses using Kriging surrogate model is illustrated in Fig. 13. Therefore, the suitable distribution function that associated with the predicted structural responses is the $W$ eibull function. Also, by increasing the beam rotation, $P D F$ is decreased.

The maximum values of beam rotation in the representative frame were obtained due to the vehicle collision with speeds of 10, 20, 30, 40 and $50 \mathrm{~km} / \mathrm{h}$ by $A N N, P R S M$, Kriging and MCS methods for three LSFs and then, these values are shown in Fig. 14. For example, by increasing the vehicle velocity from 30 to $40 \mathrm{~km} / \mathrm{h}$ and 40 to $50 \mathrm{~km} / \mathrm{h}$, the maximum values of beam rotation for MCS has increased by $41 \%$ and $24 \%$, respectively. Also, for Kriging surrogate model, by increasing the velocity of vehicle from 30 to $40 \mathrm{~km} / \mathrm{h}$ and 40 to $50 \mathrm{~km} / \mathrm{h}$, the maximum values of beam rotation have increased by $42 \%$ 
and $25 \%$, respectively. Kriging surrogate model predicted the beam rotation values with the least difference in various vehicle velocities versus $M C S$.

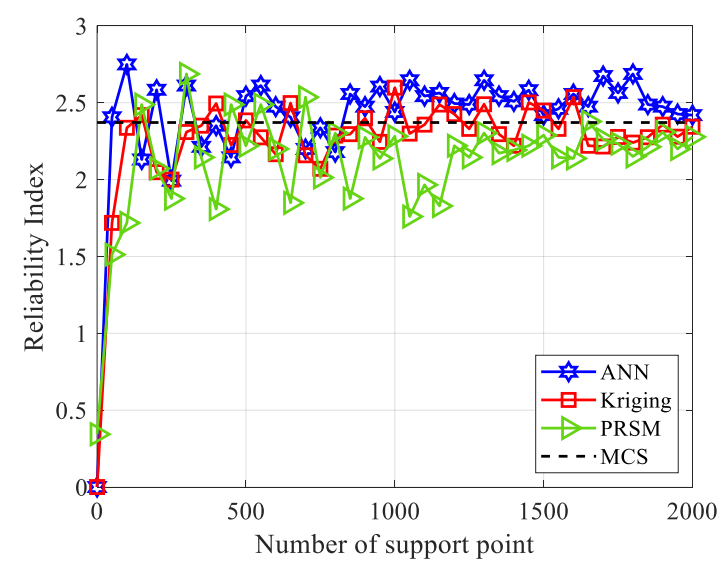

a) $L S F_{1}$

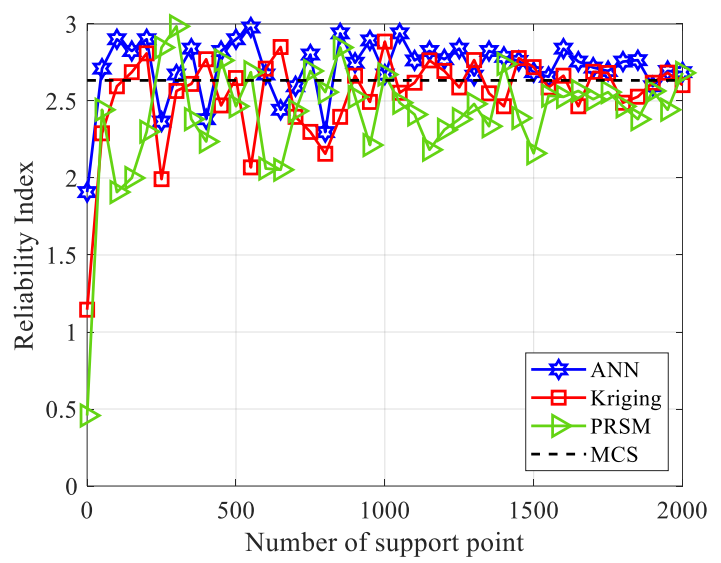

b) $\boldsymbol{L S F} F_{2}$

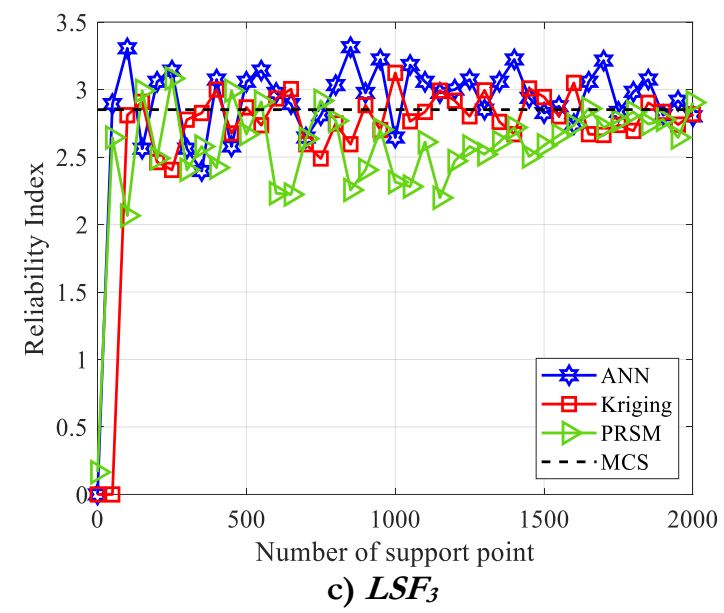

Figure 12: Reliability results of four methods with different number of support points based on the studied LSFs.

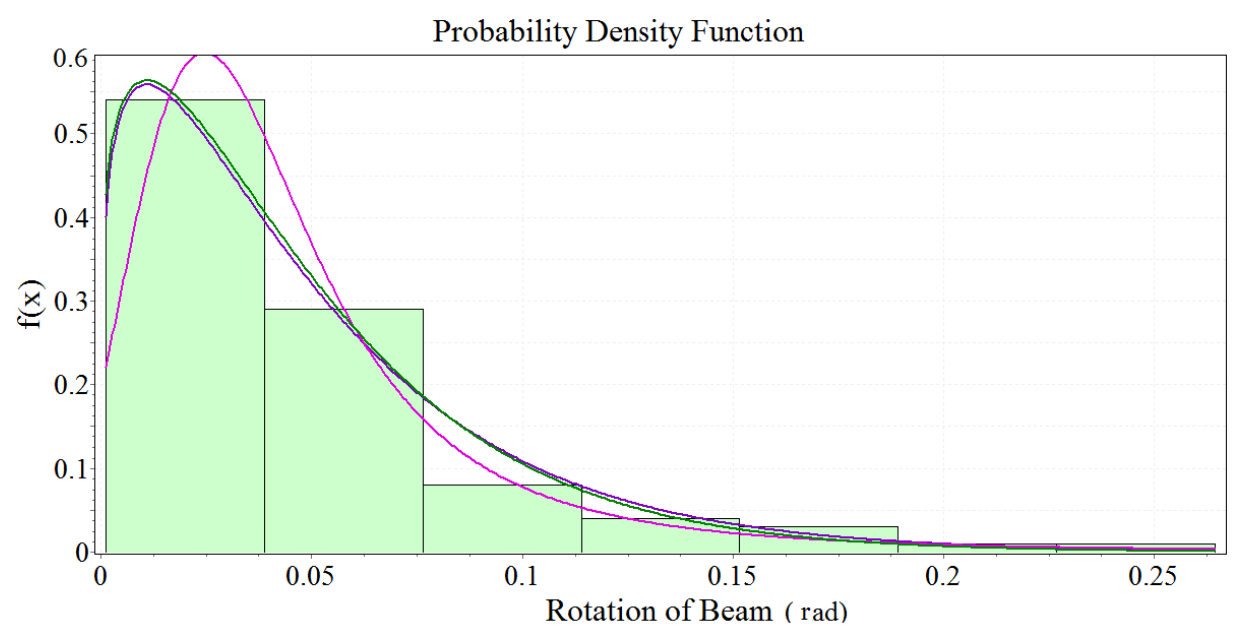

Histogram -Gen. Gamma - Gen. Logistic - Weibull

Figure 13: Frequency Histograms of the predicted structural responses using Kriging surrogate model. 


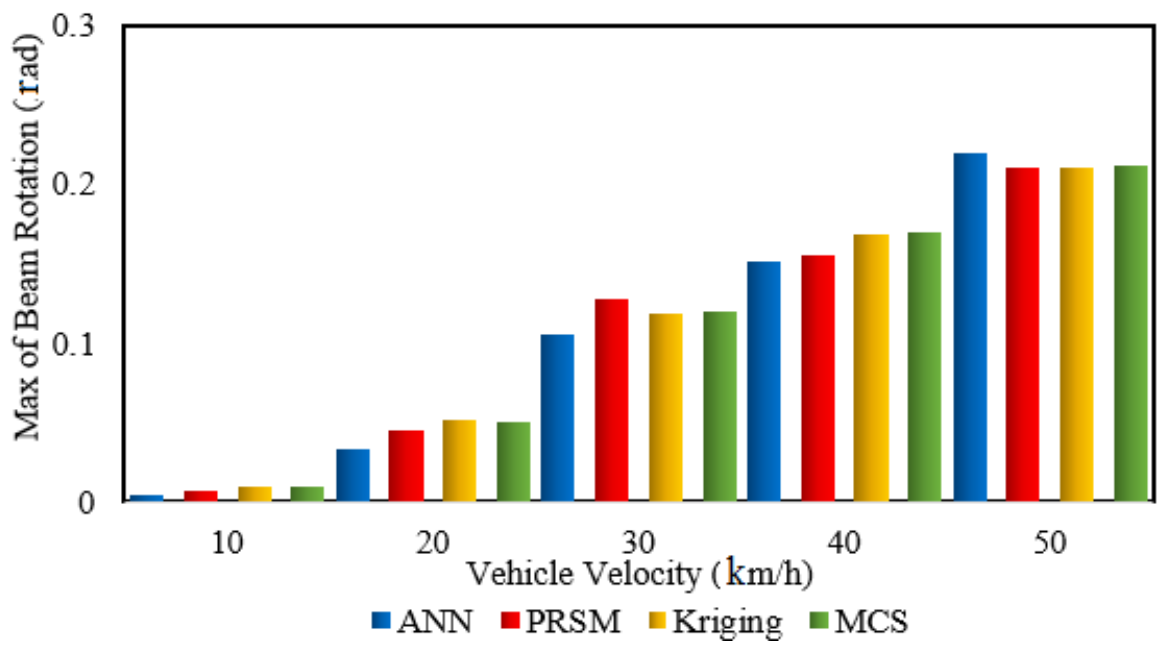

Figure 14: Reliability results of four methods with different vehicle velocities.

In the following, the reliability analysis results such as reliability index $(\beta)$, failure probability $\left(P_{f}\right)$ and the number of calling $L S F$ (\#g call) are presented for impact velocity $50 \mathrm{~km} / \mathrm{h}$, for three $L S F$ s that they are performed using $M C S, A N N, P R S M$ and Kriging methods based on Tab. 4.

\begin{tabular}{ccccc}
\hline Simulation Method & MCS & ANN & PRSM & Kriging \\
\hline \multicolumn{5}{c}{$\boldsymbol{L S F}_{\boldsymbol{1}}$} \\
\hline$\beta$ & 2.373 & 2.425 & 2.341 & 2.359 \\
\hline$P_{f}$ & 0.0088 & 0.0076 & 0.0096 & 0.0092 \\
\hline g gall & $10^{5}$ & 2000 & 2000 & 2000 \\
\hline$\beta$ & 2.633 & 2.675 & 2.668 & 2.651 \\
\hline$P_{f}$ & 0.0043 & 0.0034 & 0.0039 & 0.0040 \\
\hline$\#$ g call & $10^{5}$ & 2000 & 2000 & 2000 \\
\hline$\beta$ & 2.853 & 2.798 & 2.901 & 2.821 \\
\hline$P_{f}$ & 0.0021 & 0.0026 & 0.0018 & 0.0024 \\
\hline$\#$ g call & $10^{5}$ & 2000 & 2000 & 2000 \\
\hline
\end{tabular}

Table 4: Reliability analysis results using MCS and meta-models.

For indicating the accuracy and efficiency of Kriging meta-model versus MCS, the beam rotation values are obtained for three LSFs. Then, the comparison results of these methods are illustrated in Fig. 15. It is concluded that the failure probability of aforementioned frame is reduced by increasing the maximum permitted beam rotation. Also, by investigating this Figure, it is clear that the calculated values of failure probability by Kriging surrogate model are matched very well with MCS in different LSFs. Therefore, Kriging meta-model is introduced as the fast, suitable and optimized method for predicting the failure probability in this scenario. According to the extracted analyses results, it is concluded that the probabilistic developed framework is proper for performance evaluation of $S M R F$ structures under impact loadings without conducting numerous probabilistic analyses. However, more and special attention must be paid to training meta-models for problems with high dimensional responses. The results from the reliability analyses of the selected frame indicated that the structure was highly vulnerable to vehicle impact loadings on the corner column and Kriging surrogate model is suitable approach for predicting the collapse performance of structures. 


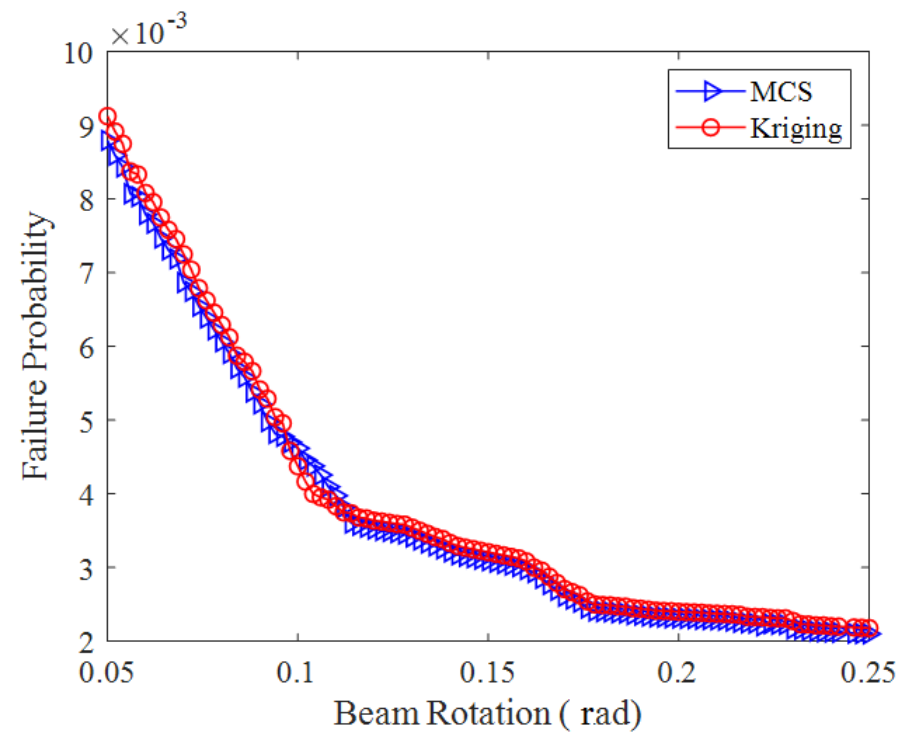

Figure 15: Comparison of the failure probability of frame for different LSFs.

\section{Fragility Analysis}

In current paper, fragility analysis is an available gadget for assessing the performance of structures under vehicle impact loading scenario. Fragility curves can be performed using the developed framework in this study by two approaches including an exact method and Kriging surrogate model. In these methods, the fragility analysis is conducted for evaluating the behavior of a prototype $S M R F$ through different damage levels. Based on Eqn. 18, the parameters such as the fragility function $F_{d}(x)$, damage measure $(D M)$, and the intensity measure (IM) are mentioned.

$$
\boldsymbol{F d}(\boldsymbol{x})=P(D M \geqslant d \mid I M=x)
$$

Therefore, the damage measure is defined by the maximum beam rotation in the damaged bay. In the following, fragility curves have been completely described as a function of gravity loads for progressive collapse assessment [57]. Also, the intensity measure in the above mentioned equation is considered as the vehicle velocity.

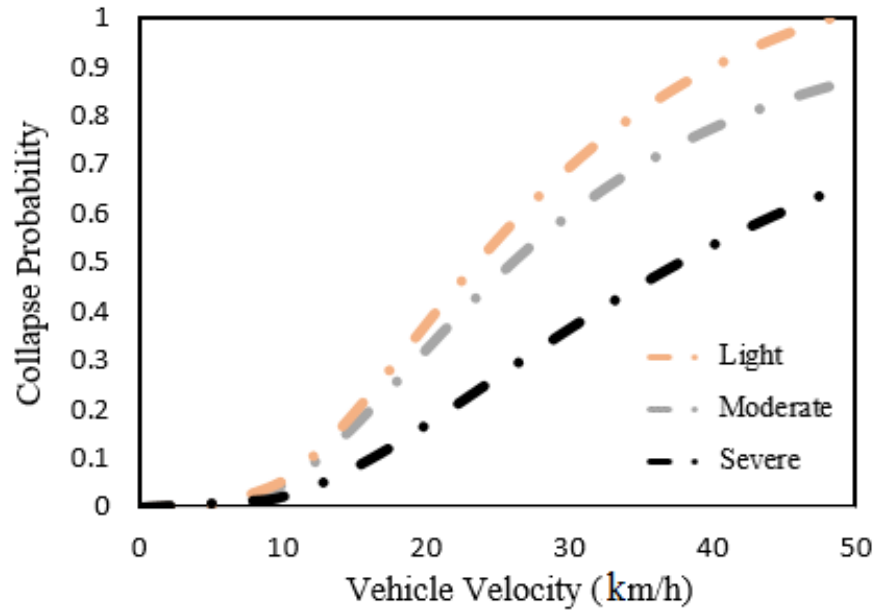

a)

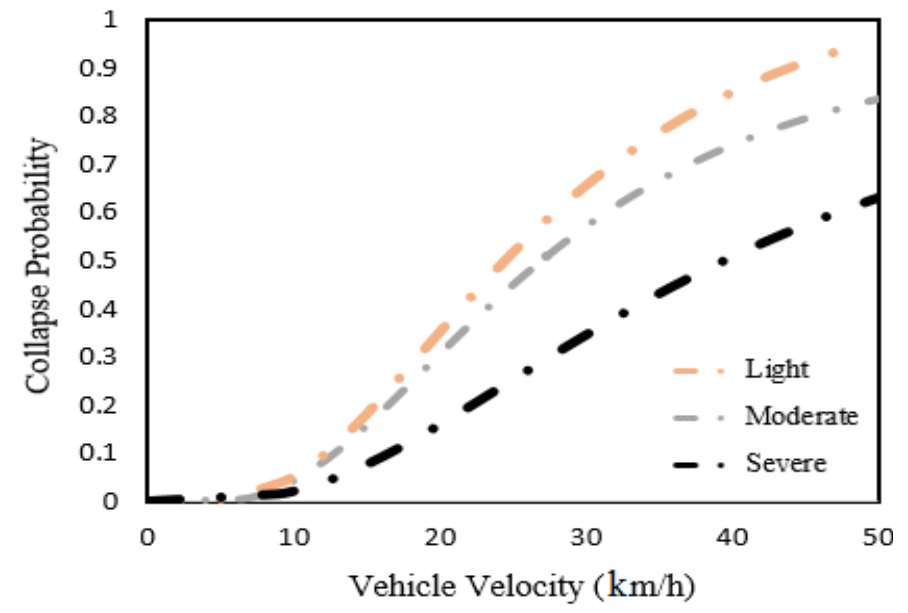

b)

Figure 16: Fragility curves for vehicle impact scenario by two methods: a) Exact method by OpenSees software; b) Kriging meta-model.

The fragility curves are plotted by two approaches such as an exact method by OpenSees software outputs and Kriging metamodel under vehicle impact loadings. Based on Fig. 16 (a) and (b), it is seen that the SMRF structure is more vulnerable to vehicle collision by two methods and its fragility curves showed that by increasing the vehicle velocity, the performance of the studied frame is changed critically. The median collapse velocities associated with the light, moderate, and severe damage 
states are presented in Tab. 5. Finally, it should be noted that, fragility curve based Kriging meta-model has the least error rate versus an exact method in three LSFs.

\begin{tabular}{ccccc}
\hline \multirow{2}{*}{ Frame } & Method & \multicolumn{3}{c}{ Median Collapse Velocity $(\mathrm{km} / \mathrm{h})$} \\
\cline { 3 - 5 } & & Light & Moderate & Severe \\
\hline \multirow{3}{*}{ 2-story } & Exact & 23.7 & 26.5 & 37.6 \\
\cline { 2 - 5 } & Kriging & 24.32 & 27.36 & 39.7 \\
\cline { 2 - 5 } & Error Rate & $2.5 \%$ & $3.1 \%$ & $5.2 \%$ \\
\hline
\end{tabular}

Table 5: Median collapse velocities using exact method and Kriging meta-model.

\section{Sensitivity Analysis based Reliability}

Sensitivity analysis based MCS

Sensitivity analysis based reliability aims studying the influence of the random parameters in the probabilistic model onto the failure probability computation. It is one of the key points in simplification and optimal design, especially in reliability problems with a large number of uncertainties. In $M C S$, sensitivity analysis is often performed by evaluating the rate of failure probability variation for each random variable [58]. By using this method, the rate of variation can be calculated as Eqn. 19:

$$
\frac{\partial \boldsymbol{P}_{f}}{\partial \boldsymbol{p}}=\frac{\partial}{\partial p} \int I[g(x)<0] f_{x(p)}(x) d x
$$

In Eqn. 19, the parameters such as: $\left(P_{f}\right)$ the probability of failure, $(P)$ a random variable, $(g(x))$ a limit state function, $\left(f_{x}\right)$ a function of probability density of both variables, and $(I)$ a counter vector are presented. Here, sensitivity analysis is performed by calling (\#g call:100,000 times) as LSF and evaluating the variation rate of failure probability related to the changes of each random variable and the results of sensitivity analysis are represented in Tab. 6 and Fig. 17. It can be found that the uncertainty parameters such as mass and velocity of vehicle and yield strength of the used materials had the maximum effect, respectively and the applied live load of the studied frame had the least effect on the failure probability calculation.

\begin{tabular}{ccc}
\hline No. & \multicolumn{2}{c}{$\begin{array}{c}\text { Failure Probability Variation for Each } \\
\text { Variable }\end{array}$} \\
1 & $\left(\partial \mathrm{P}_{\mathrm{f}}\right)(\partial \mathrm{DL})$ & 0.0095378 \\
2 & $\left(\partial \mathrm{P}_{\mathrm{f}}\right) /(\partial \mathrm{LL})$ & 0.000078194 \\
3 & $\left(\partial \mathrm{P}_{\mathrm{f}}\right) /\left(\partial \mathrm{F}_{\mathrm{y}}\right)$ & -0.045519 \\
4 & $\left(\partial \mathrm{P}_{\mathrm{f}}\right) /(\partial \mathrm{E})$ & 0.000087344 \\
5 & $(\partial \mathrm{Pf})(\partial \mathrm{L})$ & 0.00033172 \\
6 & $(\partial \mathrm{Pf}) /(\partial \mathrm{H})$ & 0.00078112 \\
7 & $(\partial \mathrm{Pf}) /(\partial \mathrm{K})$ & 0.022132 \\
8 & $(\partial \mathrm{Pf}) /(\partial \mathrm{M})$ & 0.61225 \\
9 & $\left(\partial \mathrm{P}_{\mathrm{f}}\right) /(\partial \mathrm{V})$ & 0.49325 \\
\hline
\end{tabular}

Table 6: Sensitivity analysis results of the selected frame subjected to impact loading. 


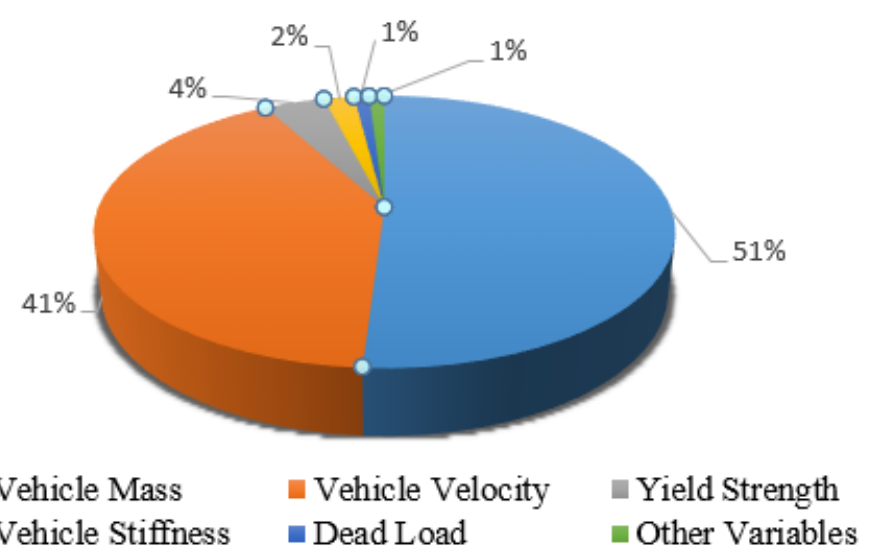

Figure 17: The contribution of different uncertainties on the total structural systems failure.

$\underline{\text { Sensitivity analysis based Sobol's }}$

Sobol's sensitivity analysis is a variance based sensitivity test. This method attempts to specify numerically the effect of input variables with different statistical distributions on the output variance of a global structural system based on probabilistic analyses. The supplementary descriptions are given about this method in Sobol' researches [59, 60]. Also, a global sensitivity analysis is used by Arwade et al. [61] for structural systems and assessing the effects of input distributions and possible approximation of the structural response function on final results. In this approach, the parameter $Y$ is introduced as the scalar output and function of $\left(x_{1}, x_{2}, \ldots, x_{k}\right)$. Then, this function is the main contribution of the $i$ th input variable alone versus to $V(Y)$ as the total output variance. This global sensitivity analysis method is named the first-order index, and this extracted index can be obtained by using the conditional variance as Eqn. 20:

$$
\boldsymbol{S}_{i}=\frac{V\left(E\left(Y \mid x_{i}\right)\right)}{V(Y)}
$$

Eqn. 20 shows that the variance is calculated while changing $x_{i}$ alone and for all possible variations of other input variables $x_{i}$, the averaging of outputs is presented. Also, for models, $\Sigma S i$ is a sum of the first-order indices that is equivalent to one. The variables $x_{i}$ and $x_{j}$ are related to each other, therefore the interaction among them can be determined as Eqn. 21:

$$
\boldsymbol{S}_{i j}=\frac{V\left(E\left(Y \mid x_{i}, x_{j}\right)\right)}{V(Y)}-S_{i}-S_{j}
$$

The total influence as another approach for global sensitivity analysis is applied in the following, which can be specified by Eqn. 22:

$$
\boldsymbol{S}_{T i}=1-\frac{V\left(E\left(Y \mid x_{\sim i}\right)\right)}{V(Y)}
$$

In Eqn. 22, the inner expectation is defined by the parameter $x_{\sim i}$ which is conditional on all variables except $x_{i}$. Thus, all sources of variation except the $i$ th variable are appertained to the term $V\left(E\left(Y \mid x_{\sim i}\right)\right.$, and the total influence of the mentioned variable can be computed by subtracting it from the total variance. The results of global sensitivity analysis are indicated in Fig. 18. Also, it shows the sensitivity indices and total influences of uncertainty parameters in current study. Both global sensitivity analyses indicate the good agreement for specifying the effective random variables on failure probability computation. These results demonstrate the effect of each random variable on the output variance. However, according to the outcomes from global sensitivity analyses, it is specified that the main factors related to the vehicle features are important in the structural responses. Secondly, material properties such as yield strength is more effective under impact 
loadings. The total influences and the first-order sensitivity analyses are compared and indicated the interaction between variables and high-order sensitivity analyses. Based on the obtained results, for instance, the total influences and the firstorder sensitivity indices for random variable vehicle velocity are obtained 0.58 and 0.49 , respectively. The comparison of these methods show that the total influences approach has more accurate versus the first-order sensitivity method. A global sensitivity analysis shows the ability of quantifying the effect of each random variable exactly. Therefore, considering uncertainties in loading, geometric and material properties is necessary for probabilistic assessment of SMRF structures subjected to vehicle impact. At last, based on the extracted results of sensitivity analyses, it is obvious that the vehicle velocity should be controlled and this action is the best way for collapse prevention of structures under vehicle impact loadings.

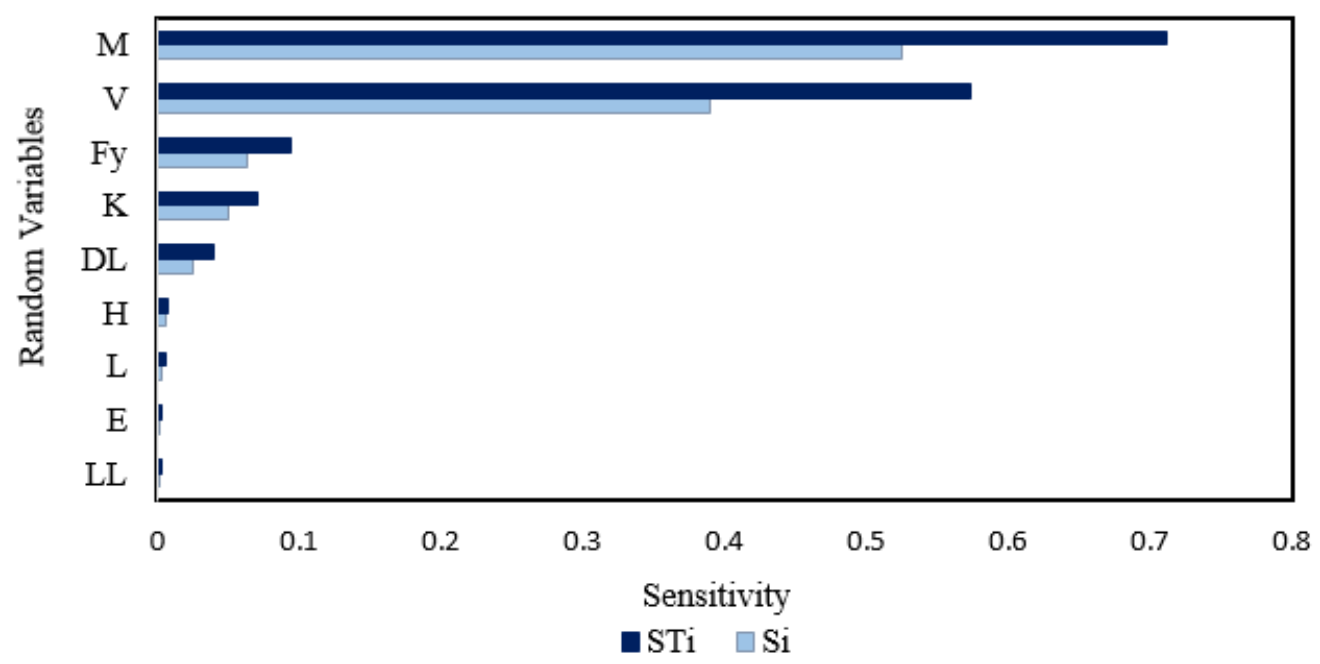

Figure 18: The importance of random variables by first-order sensitivity indices and total influences.

\section{CONCLUSION}

I $\mathrm{n}$ this paper, the probabilistic evaluation and reliability analyses of a 2-story $S M R F$ were conducted under impact loadings. The verification of the modeling was confirmed in OpenSees software with regarding to the verification of authentic studies in the technical literatures. The uncertainties of model in terms of gravity loads, material, geometric and impact loading were taken into account. Sensitivity analyses were performed to identify the major uncertainty parameters that affect the failure probability of model with two sensitivity tests such as MCS and Sobol's methods. To reduce the computational costs in the reliability analyses, three meta-models including Kriging, PRSM, and $A N N$ were constructed. Finally, fragility curves are applied by two approaches such as Kriging and Exact methods in order to determine the accuracy of meta-model and specifying the performance levels of aforementioned frame under vehicle impact. The findings are summarized as below:

- Sensitivity analyses showed that vehicle parameters were the most influential factors in failure probability calculation. The mass and velocity of vehicle and the yield strength of structural members had the greatest effect and the live load of the studied frame had the least effect on the structural failure probability computation.

- By calculating the failure probability under different vehicle collision velocities for the three LSFs, it is determined that by increasing vehicle velocity, the probability of failure increases and the reliability index decreases up to $13 \%, 20 \%$ and $18 \%$ for three $L S F$ s, respectively.

- The least error rate of Kriging surrogate model in estimating responses of studied frame in comparison with $M C S$ and other meta-models indicated that it is the best surrogate model for using in reliability analyses.

- The validity of Kriging results was confirmed though comparing those given results with the MCS results, whereas it could significantly reduce the computational processing time in comparison with MCS. Hence, Kriging is a powerful surrogate model for reliability analyses of nonlinear problems.

- Based on Kriging surrogate model, the minimum failure probability variations are increased by $75 \%, 68 \%$ and $55 \%$, with vehicle velocity augment from 20 to $40 \mathrm{~km} / \mathrm{h}$, for $L S F_{1}, L S F_{2}$ and $L S F_{3}$, respectively. Then, the maximum failure probability variations showed an increase of $56 \%, 25 \%$ and $20 \%$, with increasing vehicle velocity from 40 to $50 \mathrm{~km} / \mathrm{h}$ for aforementioned three $L S F s$, respectively. 
- According to Kriging surrogate model, by increasing the range of vehicle velocity from 10 to $20 \mathrm{~km} / \mathrm{h}, 20$ to $30 \mathrm{~km} / \mathrm{h}$, 30 to $40 \mathrm{~km} / \mathrm{h}$ and 40 to $50 \mathrm{~km} / \mathrm{h}$, the maximum values of beam rotation has increased by $80 \%, 54 \%, 42 \%$ and $25 \%$, respectively.

- The overall behavior of SMRF structure is evaluated under impact loadings using fragility analysis based Kriging, which showed that the probabilities of reaching the three different damage states are similar to the exact method that extracted from finite element results with the least computational processing time.

- The analysis results revealed that the computational efficiency is improved in terms of application the Kriging surrogate model for probabilistic assessment of $S M R F$ structures under vehicle impact loadings. However the effective methods, the performance investigation of $S M R F$ structures under this scenario is still discussed as hot research topic using soft computing methods.

\section{REFERENCES}

[1] Eurocode 1. (2006). Actions on structures - Part 1-7: general actions - accidental actions.

[2] Cormie, D., Mays, G. and Smith, P. (2009). Vehicle-borne threats and the principles of hostile vehicle mitigation, In Blast effects on buildings (2nd edition.), Thomas Telford.

[3] Severino, E. and El-Tawil, S. (2003). Collision of vehicles with bridge piers, Computational Fluid and Solid Mechanics, pp. 637-640. DOI: 10.1016/B978-008044046-0.50156-1.

[4] El-Tawil, S., Severino, E. and Fonseca, P. (2005). Vehicle collision with bridge piers, Journal of Bridge Engineering, 10(3), pp. 345-53. DOI: 10.1061/(ASCE)1084-0702(2005)10:3(345).

[5] Sharma, H., Gardoni, P. and Hurlebaus, S. (2014). Probabilistic demand model and performance based fragility estimates for RC column subject to vehicle collision, Engineering Structures, 74, pp. 86-95. DOI: 10.1016/J.ENGSTRUCT.2014.05.017.

[6] Sharma, H., Gardoni, P. and Hurlebaus, S. (2015). Performance-based probabilistic capacity models and fragility estimates for RC columns subject to vehicle collision, Computer-Aided Civil and Infrastructure Engineering, 30, pp. 555-69. DOI: $10.1111 /$ mice.12135.

[7] Kang, H. and Kim, J. (2017). Response of a steel column-footing connection subjected to vehicle impact, Structural Engineering and Mechanics, 63, pp. 125-36. DOI: 10.12989/sem.2017.63.1.125.

[8] Javidan, M.M., Kang, H., Isobe, D. and Kim, J. (2018). Computationally efficient framework for probabilistic collapse analysis of structures under extreme actions, Engineering Structures, 17, pp. 440-452. DOI: 10.1016/j.engstruct.2018.06.022.

[9] Santos, A.F., Santiago, A., Latour, M. and Rizzano, G. (2020). Robustness analysis of steel frames subjected to vehicle collisions, Structures, 25, pp. 930-942. DOI: 10.1016/j.istruc.2020.03.043.

[10] Oliveira, M.C., Teles, D.V.C. and Amorim, D.L.N.F. (2020). Shear behaviour of reinforced concrete beams under impact loads by the lumped damage framework, Frattura ed Integrità Strutturale, 53, pp. 13-25.

DOI: 10.3221 /GG-ESIS.53.02.

[11] Sadeghi, A., Kazemi, H. and Samadi, M. (2021). Probabilistic seismic analysis of steel moment-resisting frame structure including a damaged column, Structures, 33, pp. 187-200. DOI: 10.1016/j.istruc.2021.03.065.

[12] Rashki, M., Miri, M. and Azhdary Moghaddam, M. (2012). A new efficient simulation method to approximate the probability of failure and most probable point, Structural Safety, 39, pp. 22-29. DOI: 10.1016/j.strusafe.2012.06.003.

[13] Kim, J., Park, J. and Lee, T. (2011). Sensitivity analysis of steel buildings subjected to column loss, Engineering Structures, 33, pp. 421-432. DOI: 10.1016/j.engstruct.2010.10.025.

[14] Bai, L. and Zhang, Y. (2012). Collapse fragility assessment of steel roof framings with force limiting devices under transient wind loading, Frontiers of Structural and Civil Engineering, 6, pp. 199-209. DOI: 10.1007/s11709-012-01684.

[15] Gidaris, I., Taflanidis, A.A. and Mavroeidis, G.P. (2015). Kriging metamodeling in seismic risk assessment based on stochastic ground motion models. Earthquake Engineering and Structural Dynamics, 44, pp. 2377-2399. DOI: 10.1002/eqe.2586.

[16] Vazirizade, S.M., Nozhati, S. and AllamehZadeh, M. (2017). Seismic reliability assessment of structures using artificial neural network, Journal of Building Engineering, 11, pp. 230-235. DOI: 10.1016/j.jobe.2017.04.001.

[17] Hashemi, S.S., Sadeghi, K., Fazeli, A. and Zarei, M. (2019). Predicting the Weight of the Steel Moment-Resisting Frame Structures Using Artificial Neural Networks, International Journal of Steel Structures, 19, pp. 168-180. DOI: 10.1007/s13296-018-0105-z. 
[18] Hadianfard, M.A., Malekpour, S. and Momeni, M. (2018). Reliability analysis of H-section steel columns under blast loading, Structural Safety, 75, pp. 45-56. DOI: 10.1016/j.strusafe.2018.06.001.

[19] Hedayat, A.A., Ahmadi Afzadi, E., Kalantaripour, H., Morshedi, E. and Iranpour, A. (2019). A new predictive model for the minimum strength requirement of steel moment frames using artificial neural network, Soil Dynamics and Earthquake Engineering, 116, pp. 69-81. DOI: 10.1016/j.soildyn.2018.09.046.

[20] Hoseini Vaez, S.R., Mehanpour, H. and Fathali, M.A. (2020). Reliability assessment of truss structures with natural frequency constraints using metaheuristic algorithms, Journal of Building Engineering, 28. DOI: 10.1016/j.jobe.2019.101065.

[21] Rahgozar, N., Pouraminian, M. and Rahgozar, N. (2021). Reliability-based Seismic Assessment of Controlled Rocking Steel Cores, Journal of Building Engineering, 44. DOI: 10.1016/j.jobe.2021.102623.

[22] Fathi, P., Oskouei, A.N., Vahedi, K. and Petrudi, A.M. (2020). Numerical and Experimental Analysis of Stacking Sequences Effects in Composite Mechanical Joints under Impact Loadings, Frattura ed Integrità Strutturale, 53, pp. 457-473. DOI: 10.3221/IGF-ESIS.53.36.

[23] Staroverov, O.A., Strungar, E.M. and Wildemann, V.E. (2021). Evaluation of the survivability of CFRP honeycomb-cored panels in compression after impact tests, Frattura ed Integrità Strutturale, 56, pp. 1-15. DOI: 10.3221/IGF-ESIS.56.01.

[24] OpenSees. (2007). Open System for Earthquake Engineering Simulation Manual, Pacific Earthquake Engineering Research Center, University of California, Berkeley, CA. http://opensees.berkeley.edu.

[25] MATLAB. (2013). Multi paradigm numerical computing environment and proprietary programming language developed by Math Works. https://www.mathworks.com/help/matlab/

[26] Rashki, M. (2018). Hybrid control variates-based simulation method for structural reliability analysis of some problems with low failure probability, Applied Mathematical Modelling, 60, pp. 220-234. DOI: 10.1016/j.apm.2018.03.009.

[27] Chen, S., Hou, C., Zhang, H., HaiHan, L. and MinMu, T. (2020). Reliability-based evaluation for concrete-filled steel tubular (CFST) truss under flexural loading, Journal of Constructional Steel Research, 169. DOI: 10.1016/j.jcsr.2020.106018.

[28] Zhu, P., Shi, L., Yang, R. and Lin S. (2015). A new sampling-based RBDO method via score function with reweighting scheme and application to vehicle designs, Applied Mathematical Modelling, 39, pp. 4243-4256.

DOI: 10.1016/j.apm.2014.11.045.

[29] Rashki, M., Azarkish, H., Rostamian, M. and Bahrpeyma, A. (2019). Classification correction of polynomial response surface methods for accurate reliability estimation, Structural Safety, 81. DOI: 10.1016/j.strusafe.2019.101869

[30] Dubourg, V. and Sudret, B. (2014). Meta-model-based importance sampling for reliability sensitivity analysis, Structural Safety, 49, pp. 27-36. DOI: 10.1016/j.strusafe.2013.08.010.

[31] Sudret, B. (2012). Meta-models for structural reliability and uncertainty quantification, Asian Pacific Symposium on Structural Reliability and its Applications, Singapore, pp. 1-24.

[32] Hao, Y., Rong, X., Ma, L., Fan, P. and Lu, H. (2016). Uncertainty analysis on risk assessment of water inrush in karst tunnels, Mathematical Problems in Engineering, 2, pp. 1-11. DOI: 10.1155/2016/2947628.

[33] Kianifar, M.R. and Campean, F. (2020). Performance evaluation of metamodeling methods for engineering problems: towards a practitioner guide, Structural and Multidisciplinary Optimization, 61, pp. 159-186. DOI: 10.1007/s00158019-02352-1.

[34] Kaymaz, I. (2015). Application of kriging method to structural reliability problems, Structural Safety, 27, pp. $133-51$. DOI: $10.1016 /$ j.strusafe.2004.09.001.

[35] Sasena, M. (2002). Flexibility and efficiency enhancements for constrained global design optimization with Kriging approximation, Dissertation University of Michigan.

[36] Box, GEP. and Wilson, K.B. (1954). The exploration and exploitation of response surfaces: some general considerations and examples, Biometrics, 10, pp. 16-60. DOI: 10.2307/3001663.

[37] Gaspar, B., Teixeira, A. and Guedes Soares, C. Assessment of the efficiency of kriging surrogate models for structural reliability analysis, Probabilistic Engineering Mechanics, 37, pp. 24-34. DOI: 10.1016/j.probengmech.2014.03.011.

[38] Faravelli, L. (1989). Response surface approach for reliability analyses, Journal of Engineering Mechanics, 115, pp. 2763-2781. DOI: 10.1061/(ASCE)0733-9399(1989)115:12(2763).

[39] Roussouly, N., Petitjean, F. and Salaun, M. (2013). A new adaptive response surface method for reliability analysis, Probabilistic Engineering Mechanics, 32, pp. 103-115. DOI: 10.1016/j.probengmech.2012.10.001.

[40] Hadidi, A., Farahmand Azar, B. and Rafiee, A. (2017). Efficient response surface method for high dimensional structural reliability analysis, Structural Safety, 68, pp. 15-27. DOI: 10.1016/j.strusafe.2017.03.006. 
[41] Shayanfar, M., Barkhordari, M.A. and Roudak, M.A. (2017). An efficient reliability algorithm for locating design point using the combination of importance sampling concepts and response surface method, Communications in Nonlinear Science and Numerical Simulation, 47, pp. 223-237. DOI: 10.1016/j.cnsns.2016.11.021.

[42] Guimaraes, H., Matos, J.C. and Henriques, A.A. (2018). An innovative adaptive sparse response surface method for structural reliability analysis, Structural Safety, 73, pp. 12-28. DOI: 10.1016/j.strusafe.2018.02.001.

[43] Elhewy, A.H., Mesbahi, E. and Pu, Y. (2006). Reliability analysis of structures using neural network method, Probabilistic Engineering Mechanics, 21, pp. 44-53. DOI: 10.1016/J. PROBENGMECH.2005.07.002.

[44] Chojaczyk, A.A., Teixeira, A.P., Neves, L.C., Cardoso, J.B. and Soares C.G. (2015). Review and application of Artificial Neural Networks models in reliability analysis of steel structures, Structural Safety, 52, pp. 78-89. DOI: 10.1016/J.STRUSAFE.2014.09.002.

[45] ASCE 7. (2016). Minimum design loads for buildings and other structures, New York: American Society of Civil Engineers.

[46] AISC 360. (2016). Specifications for structural steel buildings, Chicago: American Institute of Steel Construction.

[47] Mujeeb, M., Pasupuleti, V.D.K. and Dongre, A. (2020). Effect of Vehicle Impact on Reinforced Concrete Structures. In: Subramaniam K., Khan M. (editors) Advances in Structural Engineering, Lecture Notes in Civil Engineering, 74, Springer, Singapore. DOI: 10.1007/978-981-15-4079-0_17.

[48] Mestrovic, D., Cizmar, D. and Miculinic L. (2008). Reliability of Concrete Columns under Vehicle Impact, Journal of WIT Transactions on the Built Environment, 98, pp. 157-165. DOI: 10.2495/SU080161.

[49] Ellingwood, B., Galambos, T.V., MacGregor, J.G. and Cornell, C.A. (1980). Development of a probability based load criterion for American National Standard A58 - building code requirement for minimum design loads in buildings and other structures, Washington, DC: National Bureau of Standards, Dept. of Commerce.

[50]JCSS. (2001). Joint Committee on Structural Safety, Probabilistic model code.

[51] CEN. (1993). European Committee for Standardization, Structural steel I and H sections - tolerances on shape and dimensions, Brussels.

[52] Zhang, X., Liu, J., Yan, Y. and Pandey, M. (2019). An Effective Approach for Reliability-Based Sensitivity Analysis with the Principle of Maximum Entropy and Fractional Moments, Entropy, 21. DOI: 10.3390/e21070649.

[53] Conrath, E.J., Krauthammer, T., Marchand, K.A. and Mlakar, P.F. (1999). Structural design for physical security - state of the practice, New York: ASCE.

[54] Ly, H.B., Le, L.M., Duong, H.T., Nguyen, T.C., Pham, T.A., Le, T-T., Le, V.M., Nguyen-Ngoc, L. and Pham, B.T. (2019). Hybrid artificial intelligence approaches for predicting critical buckling load of structural members under compression considering the influence of initial geometric imperfections, Applied Sciences, 9(11). DOI: $10.3390 /$ app9112258.

[55] Nguyen, H.Q., Ly, H-B., Tran, V.Q., Nguyen, T-A., Le, T-T. and Pham, B.T. (2020). Optimization of artificial intelligence system by evolutionary algorithm for prediction of axial capacity of rectangular concrete filled steel tubes under compression, Materials, 13(5). DOI: 10.3390/ma13051205.

[56] Pham, B.T., Nguyen-Thoi, T., Ly, H.B., Nguyen, M.D., Al-Ansari, N., Tran, V.Q. and Le, T.T. (2020). Extreme learning machine based prediction of soil shear strength: a sensitivity analysis using Monte Carlo simulations and feature backward elimination, Sustainability, 12(6). DOI: 10.3390/su12062339.

[57] Park, J. and Kim, J. (2010). Fragility analysis of steel moment frames with various seismic connections subjected to sudden loss of a column, Engineering Structures, 32, pp. 1547-55. DOI: 10.1016/J.ENGSTRUCT.2010.02.003.

[58] Wu, Y.T. and Mohanty, S. (2006). Variable screening and ranking using sampling-based sensitivity measures, Reliability Engineering \& System Safety, 91(6), pp. 634-647. DOI: 10.1016/j.ress.2005.05.004.

[59] Sobol', I.M. (1990). Sensitivity estimates for nonlinear mathematical models, Mat Model, 2, pp. 112-8.

[60] Sobol', I.M. (2001). Global sensitivity indices for nonlinear mathematical models and their Monte Carlo estimates, Mathematics and Computers in Simulation, 55, pp. 271-80. DOI: 10.1016/S0378-4754(00)00270-6.

[61] Arwade, S.R., Moradi, M. and Louhghalam, A. (2010). Variance decomposition and global sensitivity for structural systems, Engineering Structures, 32, pp. 1-10. DOI: 10.1016/J.ENGSTRUCT.2009.08.011. 